$\underline{\text { Supporting Information }}$

\title{
Asymmetric Induction in Hydrogen-Mediated Reductive Aldol Additions to $\alpha$-Amino Aldehydes Catalyzed by Rhodium: Selective Formation of syn-Stereotriads Directed by Intramolecular Hydrogen-Bonding
}

Cheol-Kyu Jung and Michael J. Krische*

University of Texas at Austin

Department of Chemistry and Biochemistry

Austin, TX 78712

$U S A$

Table of Contents

I. General Procedure ….................................................................................................. S2

II. Procedures and Characterizations ........................................................................... S3

III. Determination of Relative Stereochemistry ....................................................... S33 


\section{General Procedure}

General: Dichloromethane (DCM) was distilled from calcium hydride. Chemical reagents were purchased from Aldrich and Strem Chemicals, Inc and used without further purification. Commercially available enones were purified prior to usage. Deuterated solvents were used as received from Cambridge Isotope Laboratories. Analytical thinlayer chromatography (TLC) was carried out using $0.2-\mathrm{mm}$ commercial silica gel plates (DC-Fertigplatten Kieselgel $60 \mathrm{~F}_{254}$ ). Flash chromatography was performed on silica gel 60 (200-400 mesh). NMR spectra were recorded on a Varian Mercury 400, or Unity +300 spectrometer. ${ }^{1} \mathrm{H}$ NMR spectra were obtained at $400 \mathrm{MHz}$ or $300 \mathrm{MHz}$, as indicated. ${ }^{13} \mathrm{C}$ NMR spectra were obtained at either $100 \mathrm{MHz}$ or $75 \mathrm{MHz}$, as indicated. High resolution mass spectra were obtained on a Micromass ZAB-E spectrometer. FT-IR spectra were obtained on a Nicolet Impact 410 spectrometer. Melting points were obtained on a Thomas-Hoover Unimelt apparatus and are uncorrected. Optical rotations were obtained on an Atago POLAX-2L polarimeter. HPLC analyses were performed on a Varian ProStar system with Daicel Chiralpak, Chiralcel columns in hexanes/isopropanol solvent mixtures.

Literature Preparations of Aldehydes: $N$-Boc-L-phenylglycinal (3a) ${ }^{1}, N$-Boc-L-alaninal $(4 a)^{2}, \quad N$-Boc-L-leucinal $(5 \mathrm{a})^{1}, \quad N$-Me- $N$-Boc-L-leucinal $(N \text {-Me-5a })^{3}, \quad N$-Boc-Lphenylalaninal $(6 \mathrm{a})^{1,4}, \mathrm{~N}$-Boc-L-valinal (7a) ${ }^{1}, \mathrm{~N}$-Boc-O-TBDPS-L-serinal (8a) ${ }^{1}$ were prepared by literature methods.

General Procedure for the Coupling of Enones and Aldehydes: To a $13 \mathrm{~mm} \times 100 \mathrm{~mm}$ test-tube were added $\mathrm{Li}_{2} \mathrm{CO}_{3}(10 \mathrm{~mol} \%)$, (2-furyl $)_{3} \mathrm{P}(12 \mathrm{~mol} \%)$, $\mathrm{Rh}(\mathrm{COD})_{2} \mathrm{OTf}(5 \mathrm{~mol} \%)$, aldehyde $(100 \mathrm{~mol} \%)$ and dichloromethane $(1.0 \mathrm{M})$. Then the test-tube was sealed and the reaction system was purged with $\operatorname{Ar}(\mathrm{g})$ and $\mathrm{H}_{2}(\mathrm{~g})$ for 20 seconds each. The reaction system was placed under one atmosphere of hydrogen using a balloon and enone (300 mol\%) was added to the reaction mixture. The reaction mixture was allowed to stir at 25 ${ }^{\circ} \mathrm{C}$ for 16 hours. The reaction mixture was evaporated onto silica and the aldol products were separated by flash chromatography $\left(\mathrm{SiO}_{2}\right.$ : EtOAc/Hexane).

\footnotetext{
${ }^{1}$ Dondoni, A.; Perrone, D.; Merino, P. J. Org. Chem. 1995, 60, 8074-8080.

${ }^{2}$ Vescovi, A.; Knoll, A.; Koert, U. Organic \& Biomolecular Chem. 2003, 1, 2983-2997.

${ }^{3}$ Greenberger, L. M.; Loganzo, F. Jr.; Discafani-Marro, C. M.; Zask, A.; AyralKaloustian, S. PCT Int. Appl. 2004, 442 pp.

${ }^{4}$ The $N$-Boc-L-phenylalaninal with high optical purity was prepared by reduction of phenylalanine, Boc-protection, and oxidation. (a) McKennon, M. J.; Meyers, A. I.; Drauz, K.; Schwarn, M. J. Org. Chem. 1993, 58, 3568-3571. (b) Sharma, G. V. M.; Reddy, J. J.; Lakshmi, P. S.; Krishna, P. R. Tetrahedron Lett. 2004, 45, 6963-6965. (c) Ocejo, M.; Vicario, J. L.; Badía, D.; Carrillo, L.; Reyes, E. Synlett 2005, 2110-2112.
} 


\section{Procedures and Characterizations}

$(1 S, 2 S, 3 S)$-(2-Hydroxy-3-methyl-4-oxo-1-phenyl-pentyl)-carbamic acid tert-butyl ester (3b).<smiles>CC(=O)[C@H](C)[C@H](O)[C@H](N)c1ccccc1</smiles>

To a $13 \mathrm{~mm} \times 100 \mathrm{~mm}$ test-tube were added $\mathrm{Li}_{2} \mathrm{CO}_{3}$ (2.8 mg, $10 \mathrm{~mol} \%$ ), (2-furyl) 3 P (10.7 $\mathrm{mg}, 12 \mathrm{~mol} \%$ ), Rh(COD) $2 \mathrm{OTf}(9.0 \mathrm{mg}, 5 \mathrm{~mol} \%$ ), $N$-Boc-L-phenylglycinal (90 mg, 100 $\mathrm{mol} \%$ ) and dichloromethane $(0.38 \mathrm{~mL}, 1.0 \mathrm{M})$. Then the test-tube was sealed and the reaction system was purged with $\operatorname{Ar}(\mathrm{g})$ and $\mathrm{H}_{2}(\mathrm{~g})$ for 20 seconds each. The reaction system was placed under one atmosphere of hydrogen using a balloon and methyl vinyl ketone (94 $\mu \mathrm{L}, 300 \mathrm{~mol} \%$ ) was added to the reaction mixture. The reaction mixture was allowed to stir at $25{ }^{\circ} \mathrm{C}$ for 16 hours. The title compound was purified by flash chromatography $\left(\mathrm{SiO}_{2}\right.$ : EtOAc/Hexane) to afford $95 \mathrm{mg}$ as viscous yellowish oil (81\% yield).

TLC: $\mathrm{R}_{f} 0.5$ (Hexane/EtOAc, 2/1).

$\underline{{ }^{1} \mathbf{H} \text { NMR }}\left(400 \mathrm{MHz}, \mathrm{CDCl}_{3}\right): \delta 7.26-7.37(\mathrm{~m}, 5 \mathrm{H}), 5.42$ (d, J=7.9 Hz, 1H), 4.65 (br, 1H), 4.11 (br, 1H), 2.67 (br, 1H), 2.56-2.63 (m, 1H), 2.17 (s, 3H), 1.42 (br, 9H), 1.23 (d, J= $7.2 \mathrm{~Hz}, 3 \mathrm{H})$.

$\underline{{ }^{13} \mathrm{C} \mathrm{NMR}}\left(100 \mathrm{MHz}, \mathrm{CDCl}_{3}\right): \delta 212.3,156.0,140.4,128.7,127.6,126.6,79.7,74.9,56.9$, 48.6, 29.2, 28.3, 11.8 .

HRMS: Calcd [M+1] for $\mathrm{C}_{17} \mathrm{H}_{25} \mathrm{NO}_{4}$ : 308.1862; Found: 308.1862.

FTIR (film): 3440, 3155, 2981, 2253, 1794, 1705, 1494, 1369, 1251, 1167, 1094, 904 $\mathrm{cm}^{-1}$.

$[\alpha]_{\mathbf{D}}=+30.0\left(\mathrm{c}=0.50, \mathrm{CHCl}_{3}\right)$. 
<smiles>CC(=O)OC(=O)N[C@@H](c1ccccc1)[C@@H](O)[C@H](C)C(C)=O</smiles>

\section{${ }^{1}$ H NMR Spectrum}

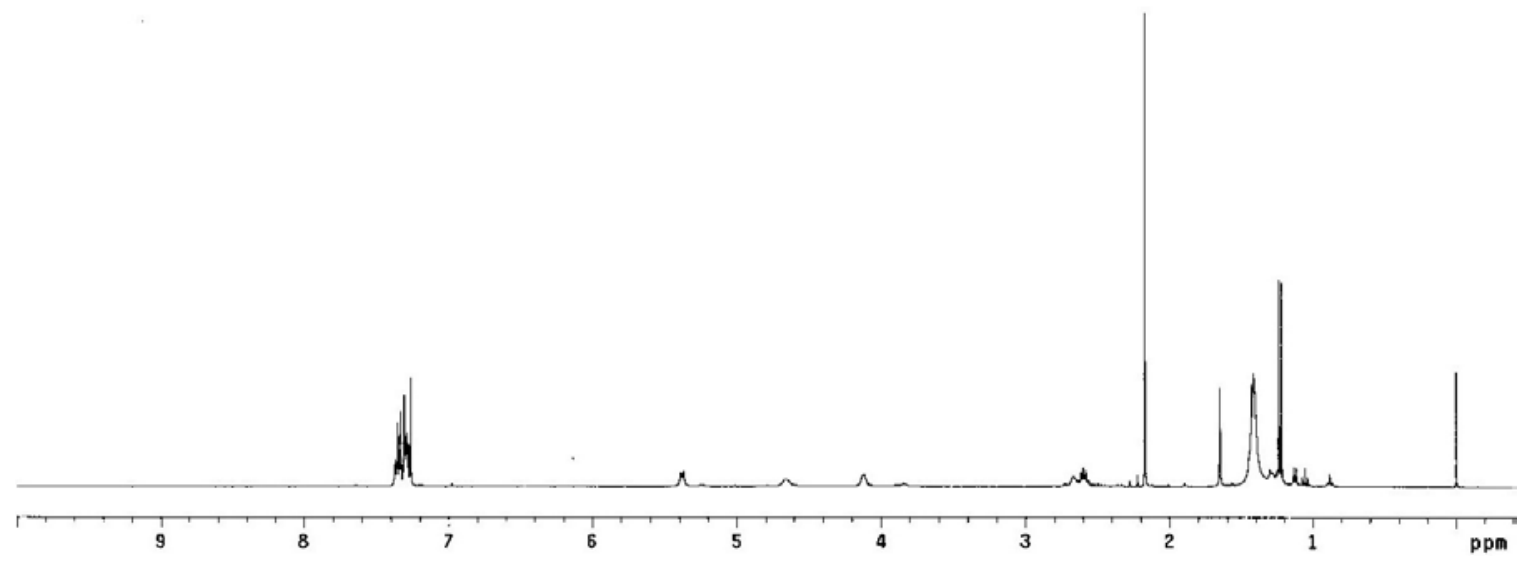

\section{${ }^{13}$ C NMR Spectrum}

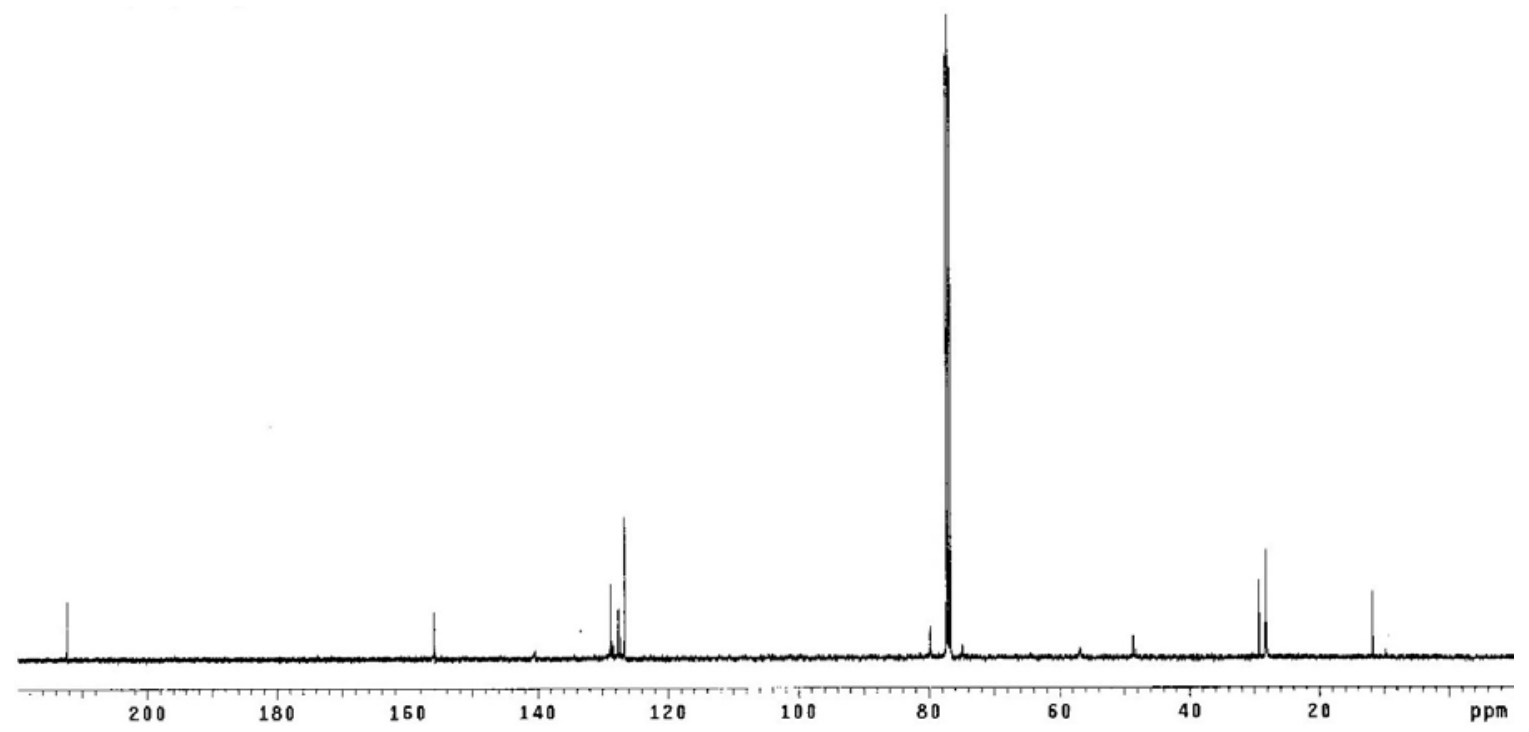


$(1 S, 2 S, 3 S)-(2-H y d r o x y-3-m e t h y l-4-0 x 0-1-p h e n y l-h e x y l)-c a r b a m i c \quad$ acid tert-butyl ester (3c).<smiles>CCC(=O)OC(=O)N[C@H](c1ccccc1)[C@@H](O)[C@@H](C)C(=O)OCc1ccccc1</smiles>

To a $13 \mathrm{~mm} \times 100 \mathrm{~mm}$ test-tube were added $\mathrm{Li}_{2} \mathrm{CO}_{3}(2.4 \mathrm{mg}, 10 \mathrm{~mol} \%)$, (2-furyl) ${ }_{3} \mathrm{P}(9.0$ mg, $12 \mathrm{~mol} \%$ ), Rh(COD) 2 OTf (7.5 mg, 5 mol\%), $N$-Boc-L-phenylglycinal (77 mg, 100 $\mathrm{mol} \%)$ and dichloromethane $(0.32 \mathrm{~mL}, 1.0 \mathrm{M})$. Then the test-tube was sealed and the reaction system was purged with $\operatorname{Ar}(\mathrm{g})$ and $\mathrm{H}_{2}(\mathrm{~g})$ for 20 seconds each. The reaction system was placed under one atmosphere of hydrogen using a balloon and ethyl vinyl ketone (100 $\mu \mathrm{L}, 300 \mathrm{~mol} \%)$ was added to the reaction mixture. The reaction mixture was allowed to stir at $25{ }^{\circ} \mathrm{C}$ for 16 hours. The title compound was purified by flash chromatography $\left(\mathrm{SiO}_{2}\right.$ : EtOAc/Hexane) to afford $84 \mathrm{mg}$ as a white solid (80 \% yield).

TLC : $\mathrm{R}_{f} 0.6$ (Hexane/EtOAc, 2/1).

${ }^{1}$ H NMR $\left(400 \mathrm{MHz}, \mathrm{CDCl}_{3}\right): \delta 7.23-7.35(\mathrm{~m}, 5 \mathrm{H}), 5.46(\mathrm{~d}, J=8.2 \mathrm{~Hz}, 1 \mathrm{H}), 4.62(\mathrm{br}, 1 \mathrm{H})$, $4.08(\mathrm{br}, 1 \mathrm{H}), 2.76$ (br, 1H), 2.66 (quintet, $J=6.9 \mathrm{~Hz}, 1 \mathrm{H}), 2.54\left(\mathrm{dq}, \mathrm{A}\right.$ of $\mathrm{ABX}, J_{A B}=$ $\left.18.1 \mathrm{~Hz}, J_{A X}=7.2 \mathrm{~Hz}, 1 \mathrm{H}\right), 2.42\left(\mathrm{dq}, \mathrm{B}\right.$ of ABX, $\left.J_{A B}=18.1 \mathrm{~Hz}, J_{B X}=7.2 \mathrm{~Hz}, 1 \mathrm{H}\right), 1.41$ (br, 9H), 1.20 (d, $J=7.2 \mathrm{~Hz}, 3 \mathrm{H}), 1.03$ (d, $J=7.2 \mathrm{~Hz}, 3 \mathrm{H})$.

${ }^{13} \mathbf{C ~ N M R}\left(100 \mathrm{MHz}, \mathrm{CDCl}_{3}\right): \delta 215.0,155.8,140.6,128.6,127.4,126.5,79.7,75.1,56.7$, $47.8,35.2,28.2,12.4,7.5$.

HRMS: Calcd [M+1] for $\mathrm{C}_{18} \mathrm{H}_{27} \mathrm{NO}_{4}$ : 322.2018; Found: 322.2020.

FTIR (film): 3155, 2982, 2384, 2254, 1794, 1708, 1602, 1550, 1468, 1381, 1166, 1095 , $911 \mathrm{~cm}^{-1}$.

MP: $88-89^{\circ} \mathrm{C}$.

$[\alpha]_{\mathbf{D}}=+21.7\left(\mathrm{c}=0.69, \mathrm{CHCl}_{3}\right)$. 
<smiles>CCC(=O)OC(=O)N[C@H](c1ccccc1)[C@@H](O)[C@@H](C)C(=O)OCc1ccccc1</smiles>

$\underline{{ }^{1} \text { H NMR Spectrum }}$

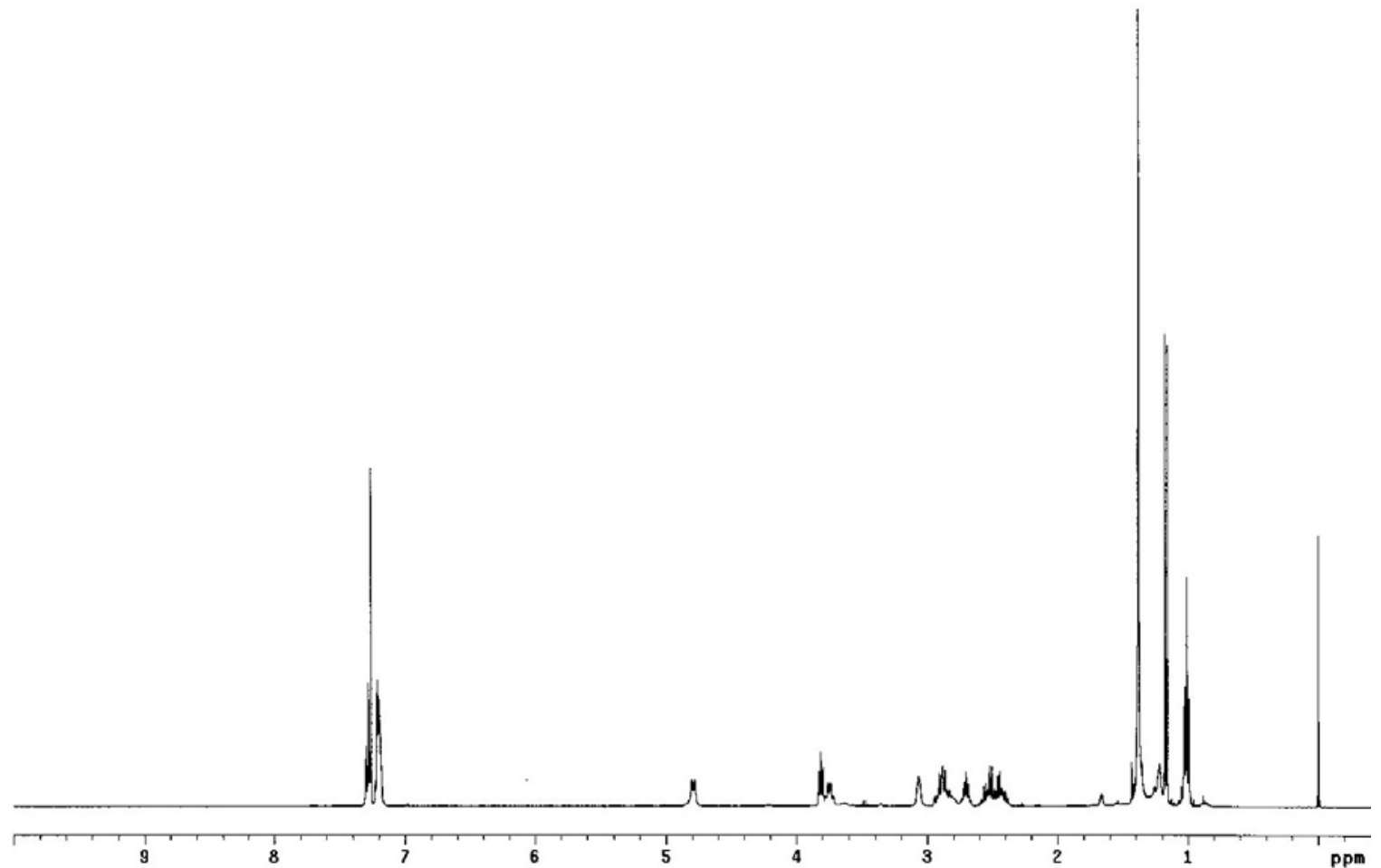

\section{${ }^{13}$ C NMR Spectrum}

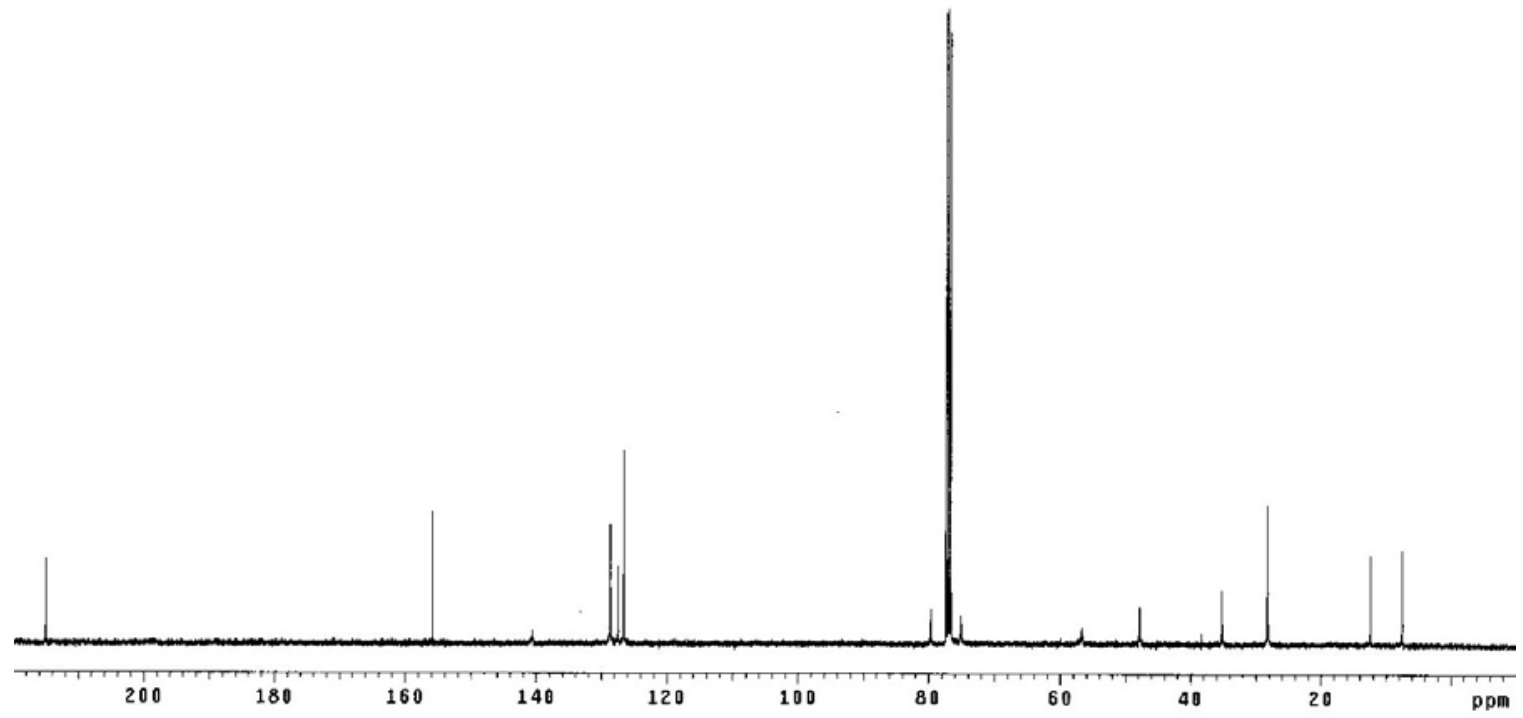




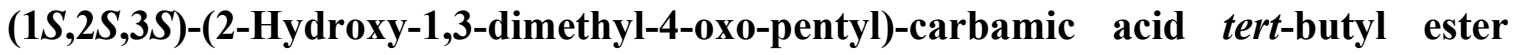
(4b).<smiles>CC(=O)N[C@@H](C)[C@H](O)[C@H](C)C(C)=O</smiles>

To a $13 \mathrm{~mm} \times 100 \mathrm{~mm}$ test-tube were added $\mathrm{Li}_{2} \mathrm{CO}_{3}(3.8 \mathrm{mg}, 10 \mathrm{~mol} \%)$, (2-furyl) ${ }_{3} \mathrm{P}$ (14.2 mg, $12 \mathrm{~mol} \%$ ), Rh(COD) $)_{2} \mathrm{OTf}$ (11.9 mg, $5 \mathrm{~mol} \%$ ), $N$-Boc-L-alaninal (88 mg, 100 $\mathrm{mol} \%)$ and dichloromethane $(0.51 \mathrm{~mL}, 1.0 \mathrm{M})$. Then the test-tube was sealed and the reaction system was purged with $\operatorname{Ar}(\mathrm{g})$ and $\mathrm{H}_{2}(\mathrm{~g})$ for 20 seconds each. The reaction system was placed under one atmosphere of hydrogen using a balloon and methyl vinyl ketone $(125 \mu \mathrm{L}, 300 \mathrm{~mol} \%)$ was added to the reaction mixture. The reaction mixture was allowed to stir at $25{ }^{\circ} \mathrm{C}$ for 16 hours. The title compound was purified by flash chromatography $\left(\mathrm{SiO}_{2}\right.$ : EtOAc/Hexane) to afford $98 \mathrm{mg}$ as colorless oil (79\% yield).

$\underline{\text { TLC }}: \mathrm{R}_{f} 0.45$ (Hexane/EtOAc, 2/1).

${ }^{1}$ H NMR $\left(400 \mathrm{MHz}, \mathrm{CDCl}_{3}\right): \delta 4.84(\mathrm{~d}, J=8.5 \mathrm{~Hz}, 1 \mathrm{H}), 3.73-3.76(\mathrm{~m}, 1 \mathrm{H}), 3.68(\mathrm{br}, 1 \mathrm{H})$, 3.15 (br, 1H), 2.70 (quintet, $J=7.0 \mathrm{~Hz}, 1 \mathrm{H}), 2.21(\mathrm{~s}, 3 \mathrm{H}), 1.44(\mathrm{~s}, 9 \mathrm{H}), 1.20$ (d, $J=7.2$ $\mathrm{Hz}, 3 \mathrm{H}), 1.18$ (d, $J=6.5 \mathrm{~Hz}, 3 \mathrm{H})$.

${ }^{13} \mathrm{C}$ NMR $\left(100 \mathrm{MHz}, \mathrm{CDCl}_{3}\right): \delta 212.7,156.1,79.4,74.8,49.4,48.5,29.2,28.3,18.6$, 12.1 .

HRMS: Calcd [M+1] for $\mathrm{C}_{12} \mathrm{H}_{23} \mathrm{NO}_{4}$ : 246.1705; Found: 246.1707.

FTIR (film): 3435, 3055, 2981, 2935, 2305, 1703, 1506, 1454, 1393, 1367, 1266, 1167 , $1079,1024,992,896 \mathrm{~cm}^{-1}$.

$[\alpha]_{\mathbf{D}}=-24.3\left(\mathrm{c}=2.47, \mathrm{CHCl}_{3}\right)$. 
<smiles>CC(=O)N[C@@H](C)[C@H](O)[C@@H](C)C(C)=O</smiles>

\section{${ }^{1}$ H NMR Spectrum}

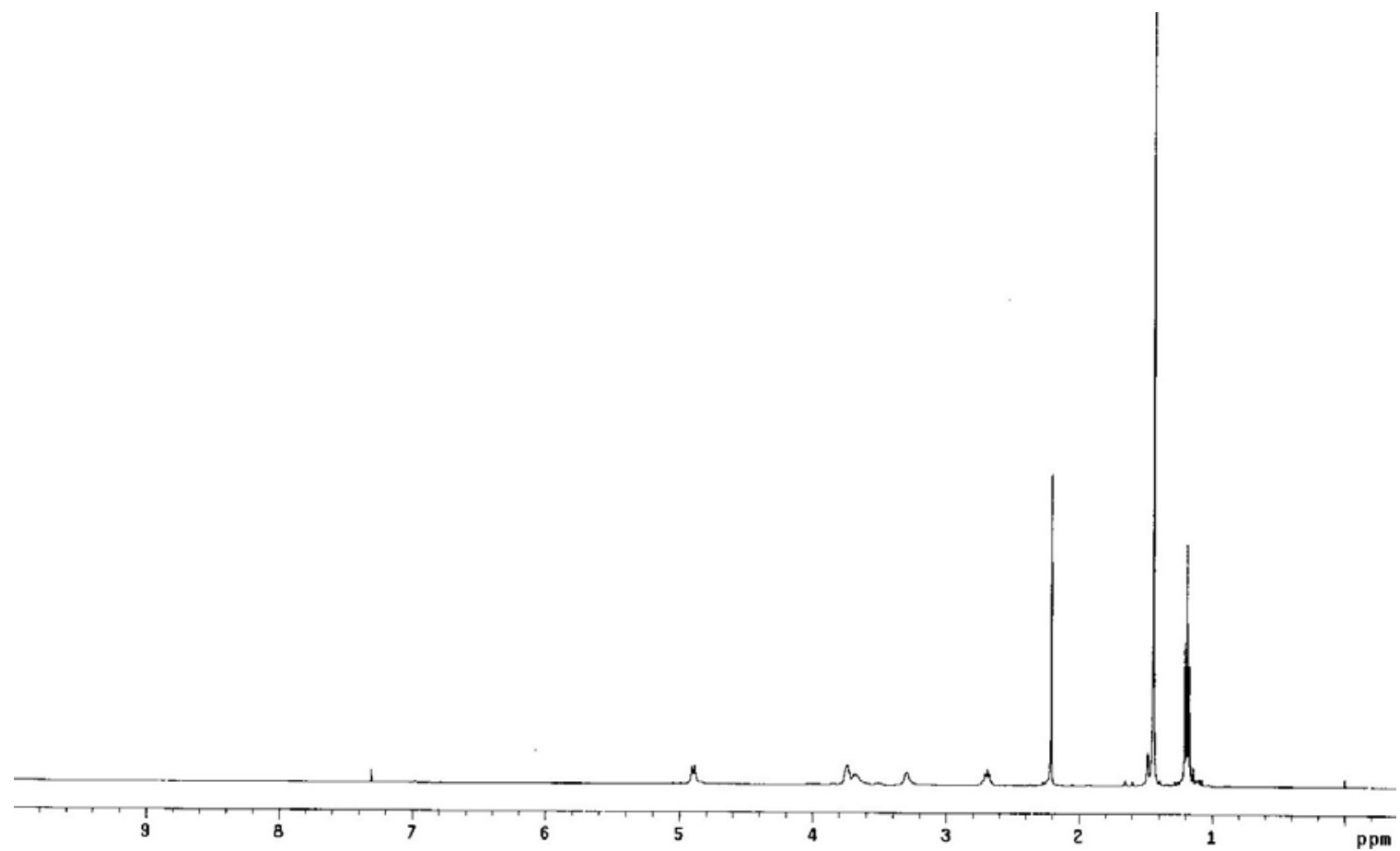

\section{${ }^{13}$ C NMR Spectrum}

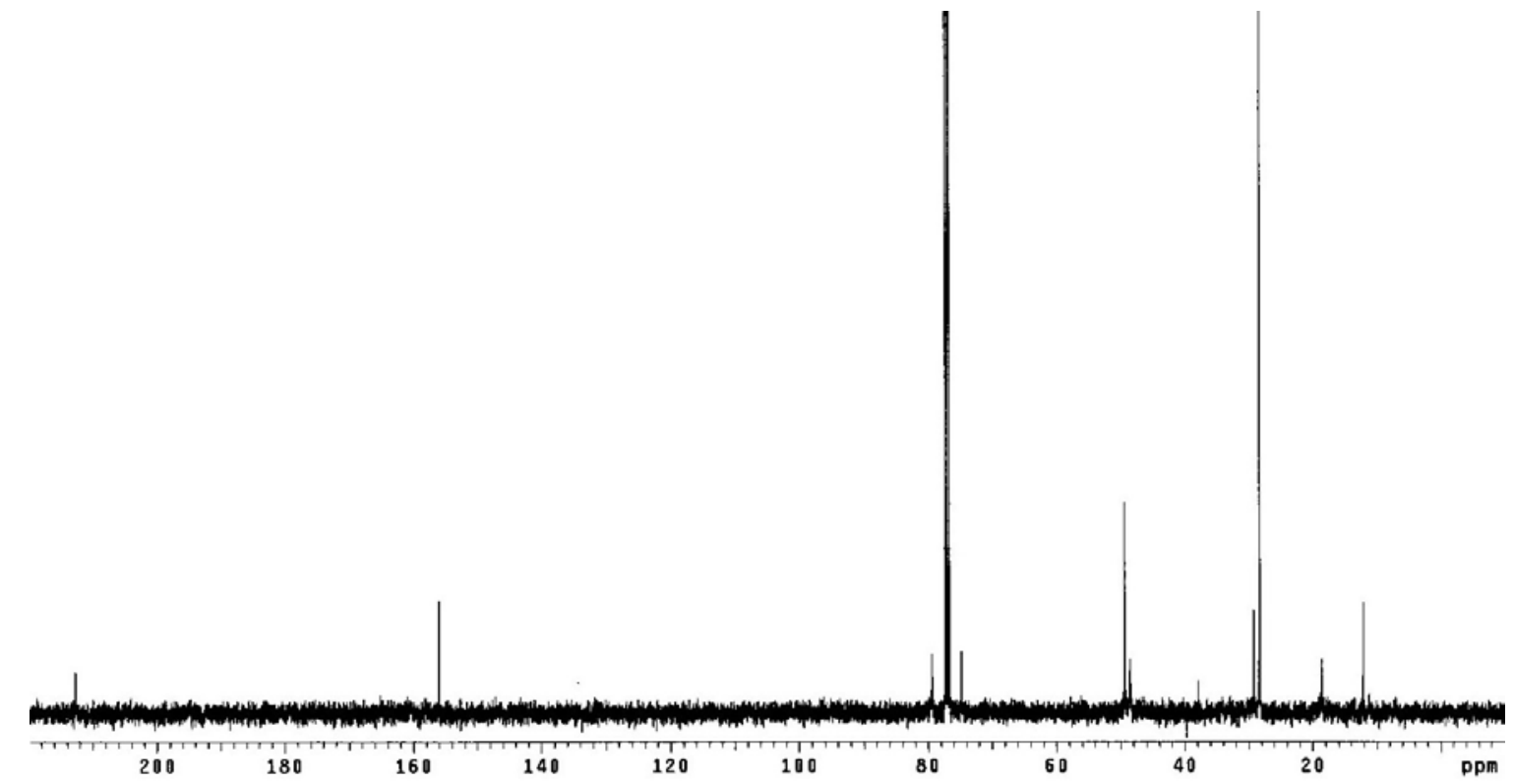


$(1 S, 2 S, 3 S)$-(2-Hydroxy-1,3-dimethyl-4-oxo-hexyl)-carbamic acid tert-butyl ester (4c).<smiles>CCC(=O)[C@H](C)[C@@H](O)[C@H](C)NC(=O)OC(C)(C)C</smiles>

To a $13 \mathrm{~mm} \times 100 \mathrm{~mm}$ test-tube were added $\mathrm{Li}_{2} \mathrm{CO}_{3}(3.8 \mathrm{mg}, 10 \mathrm{~mol} \%$ ), (2-furyl) 3 P (14.2 mg, $12 \mathrm{~mol} \%$ ), Rh(COD) ${ }_{2} \mathrm{OTf}$ (11.9 mg, 5 mol\%), $N$-Boc-L-alaninal (88 mg, $100 \mathrm{~mol} \%$ ) and dichloromethane $(0.51 \mathrm{~mL}, 1.0 \mathrm{M})$. Then the test-tube was sealed and the reaction system was purged with $\operatorname{Ar}(\mathrm{g})$ and $\mathrm{H}_{2}(\mathrm{~g})$ for 20 seconds each. The reaction system was placed under one atmosphere of hydrogen using a balloon and ethyl vinyl ketone $(152 \mu \mathrm{L}$, $300 \mathrm{~mol} \%$ ) was added to the reaction mixture. The reaction mixture was allowed to stir at $25{ }^{\circ} \mathrm{C}$ for 16 hours. The title compound was purified by flash chromatography $\left(\mathrm{SiO}_{2}\right.$ : EtOAc/Hexane) to afford $121 \mathrm{mg}$ as colorless oil (92\% yield).

TLC $: \mathrm{R}_{f} 0.6$ (Hexane/EtOAc, 2/1).

${ }^{1}$ H NMR $\left(400 \mathrm{MHz}, \mathrm{CDCl}_{3}\right): \delta 4.71(\mathrm{br}, 1 \mathrm{H}), 3.73-3.77(\mathrm{~m}, 1 \mathrm{H}), 3.65(\mathrm{br}, 1 \mathrm{H}), 2.85(\mathrm{br}$, 1H), 2.67-2.74 (m, 1H), $1.44(\mathrm{~s}, 9 \mathrm{H}), 1.18(\mathrm{~d}, J=7.2 \mathrm{~Hz}, 3 \mathrm{H}), 1.05$ (t, $J=7.2 \mathrm{~Hz}, 3 \mathrm{H})$.

${ }^{13} \mathbf{C ~ N M R}\left(75 \mathrm{MHz}, \mathrm{CDCl}_{3}\right): \delta 215.4,156.0,79.4,75.0,48.5,35.0,28.5,28.3,18.8,12.3$, 7.5 .

HRMS: Calcd [M+1] for $\mathrm{C}_{13} \mathrm{H}_{25} \mathrm{NO}_{4}$ : 260.1862; Found: 260.1860 .

FTIR (film): 3435, 3055, 2980, 2937, 1703, 1506, 1456, 1367, 1266, 1166, 1102, 1025 , $976,896 \mathrm{~cm}^{-1}$.

$[\alpha]_{\mathbf{D}}=-24.0\left(\mathrm{c}=2.08, \mathrm{CHCl}_{3}\right)$. 
$\overbrace{\mathrm{CH}_{3}}^{\stackrel{\mathrm{C}}{\mathrm{O}}} \stackrel{\mathrm{O} \mathrm{H}_{3}}{\mathrm{OH}} \mathrm{CH}_{3}$

\section{${ }^{1}$ H NMR Spectrum}

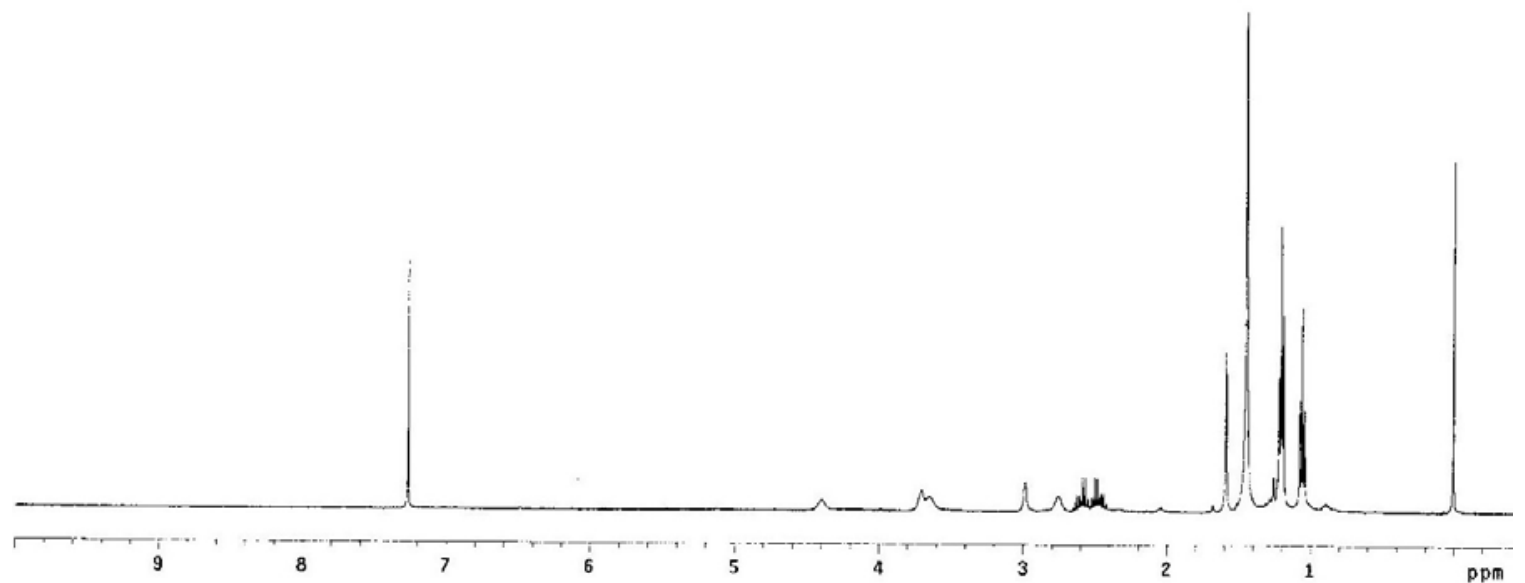

\section{${ }^{13}$ C NMR Spectrum}

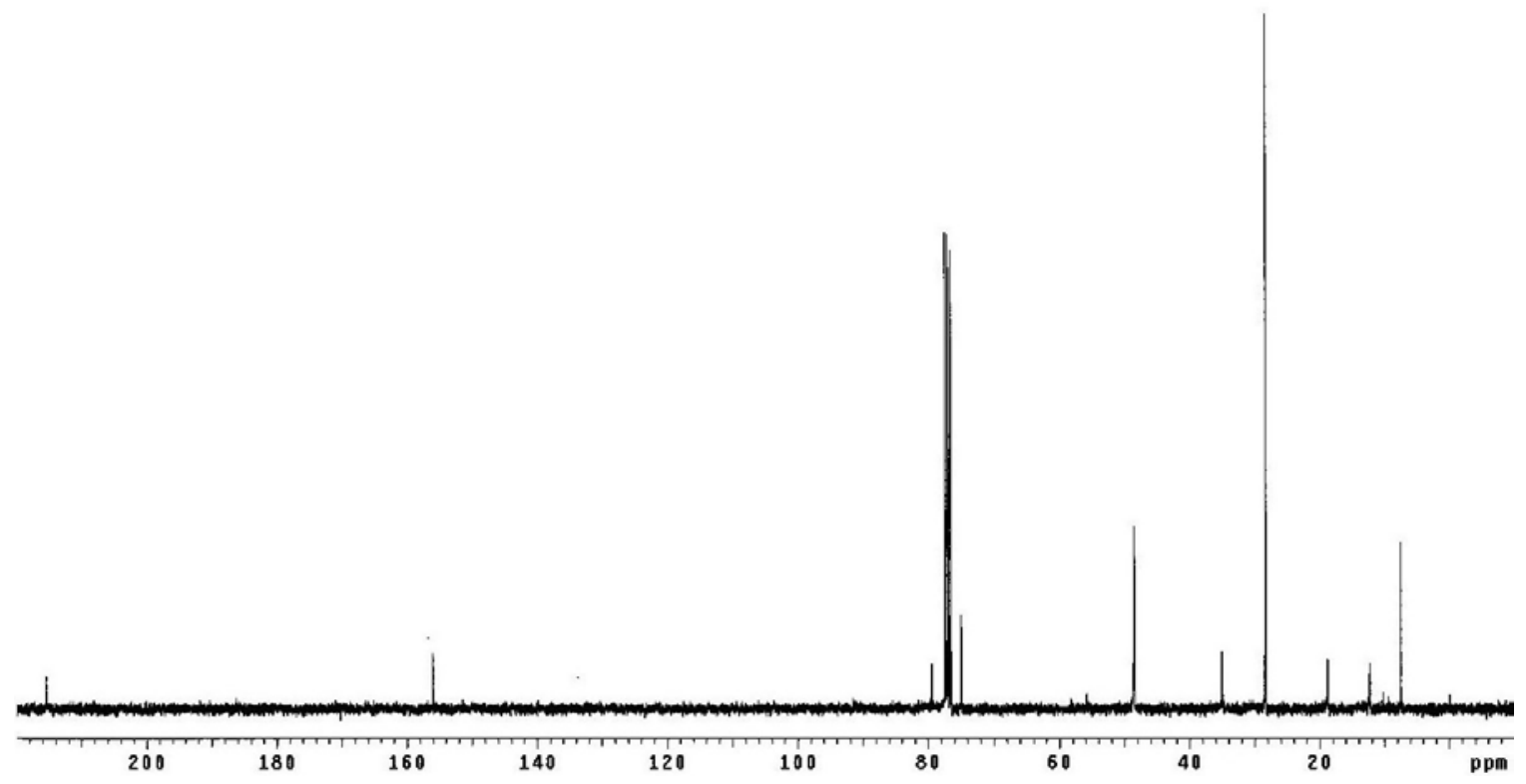


$(1 S, 2 S, 3 S)-(2-H y d r o x y-1-i s o b u t y l-3-m e t h y l-4-0 x 0-p e n t y l)-c a r b a m i c \quad$ acid tert-butyl ester (5b).

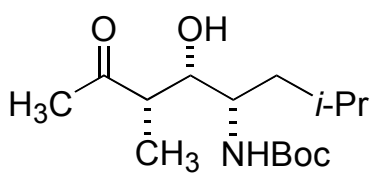

To a $13 \mathrm{~mm} \times 100 \mathrm{~mm}$ test-tube were added $\mathrm{Li}_{2} \mathrm{CO}_{3}(3.8 \mathrm{mg}, 10 \mathrm{~mol} \%$ ), (2-furyl) 3 P (14.2 mg, $12 \mathrm{~mol} \%), \operatorname{Rh}(\mathrm{COD})_{2} \mathrm{OTf}$ (11.9 mg, $\left.5 \mathrm{~mol} \%\right), N$-Boc-L-leucinal (111 mg, 100 $\mathrm{mol} \%)$ and dichloromethane $(0.51 \mathrm{~mL}, 1.0 \mathrm{M})$. Then the test-tube was sealed and the reaction system was purged with $\operatorname{Ar}(\mathrm{g})$ and $\mathrm{H}_{2}(\mathrm{~g})$ for 20 seconds each. The reaction system was placed under one atmosphere of hydrogen using a balloon and methyl vinyl ketone $(125 \mu \mathrm{L}, 300 \mathrm{~mol} \%)$ was added to the reaction mixture. The reaction mixture was allowed to stir at $25{ }^{\circ} \mathrm{C}$ for 16 hours. The title compound was purified by flash chromatography $\left(\mathrm{SiO}_{2}\right.$ : EtOAc/Hexane) to afford $101 \mathrm{mg}$ as colorless oil (68\% yield).

TLC : $\mathrm{R}_{f} 0.35$ (Hexane/EtOAc, 3/1).

1H NMR $\left(400 \mathrm{MHz}, \mathrm{CDCl}_{3}\right): \delta 4.70(\mathrm{~d}, J=9.2 \mathrm{~Hz}, 1 \mathrm{H}), 3.76-3.80(\mathrm{~m}, 1 \mathrm{H}), 3.60-3.66(\mathrm{~m}$, $1 \mathrm{H}), 2.90(\mathrm{~d}, J=5.8 \mathrm{~Hz}, 1 \mathrm{H}), 2.72$ (quintet, $J=7.2 \mathrm{~Hz}, 1 \mathrm{H}), 2.21(\mathrm{~s}, 3 \mathrm{H}), 1.60-1.68$ (m, $1 \mathrm{H}), 1.44-1.50(\mathrm{~m}, 1 \mathrm{H}), 1.44(\mathrm{~s}, 9 \mathrm{H}), 1.26-1.34(\mathrm{~m}, 1 \mathrm{H}), 1.20(\mathrm{~d}, J=7.2 \mathrm{~Hz}, 3 \mathrm{H}), 0.92$ (d, $J=6.5 \mathrm{~Hz}, 3 \mathrm{H}), 0.91(\mathrm{~d}, J=6.5 \mathrm{~Hz}, 3 \mathrm{H})$.

${ }^{13} \mathbf{C ~ N M R}\left(100 \mathrm{MHz}, \mathrm{CDCl}_{3}\right): \delta 212.9,156.2,79.3,74.0,50.9,49.5,41.9,29.4,28.3$, $24.8,23.0,22.1,12.9$.

HRMS: Calcd [M+1] for $\mathrm{C}_{15} \mathrm{H}_{29} \mathrm{NO}_{4}$ : 288.2175; Found: 288.2178.

FTIR (film): 3374, 2960, 2871, 1711, 1564, 1502, 1453, 1367, 1251, 1166, 1042, 955, $868 \mathrm{~cm}^{-1}$.

$[\alpha]_{\mathbf{D}}=-42.5\left(\mathrm{c}=2.24, \mathrm{CHCl}_{3}\right)$. 


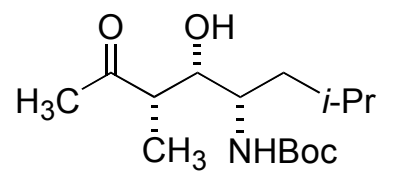

\section{${ }^{1}$ H NMR Spectrum}

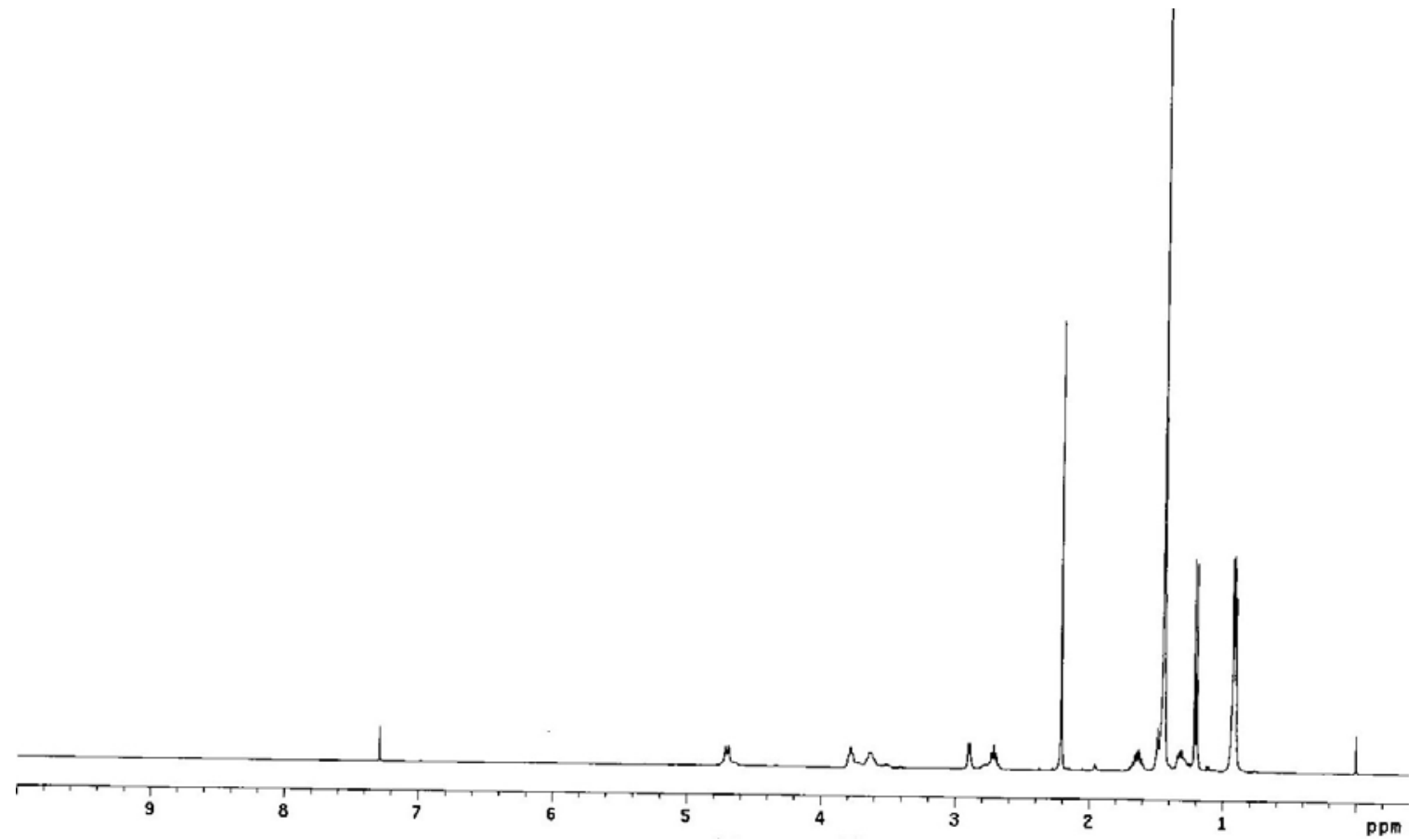

\section{${ }^{13}$ C NMR Spectrum}

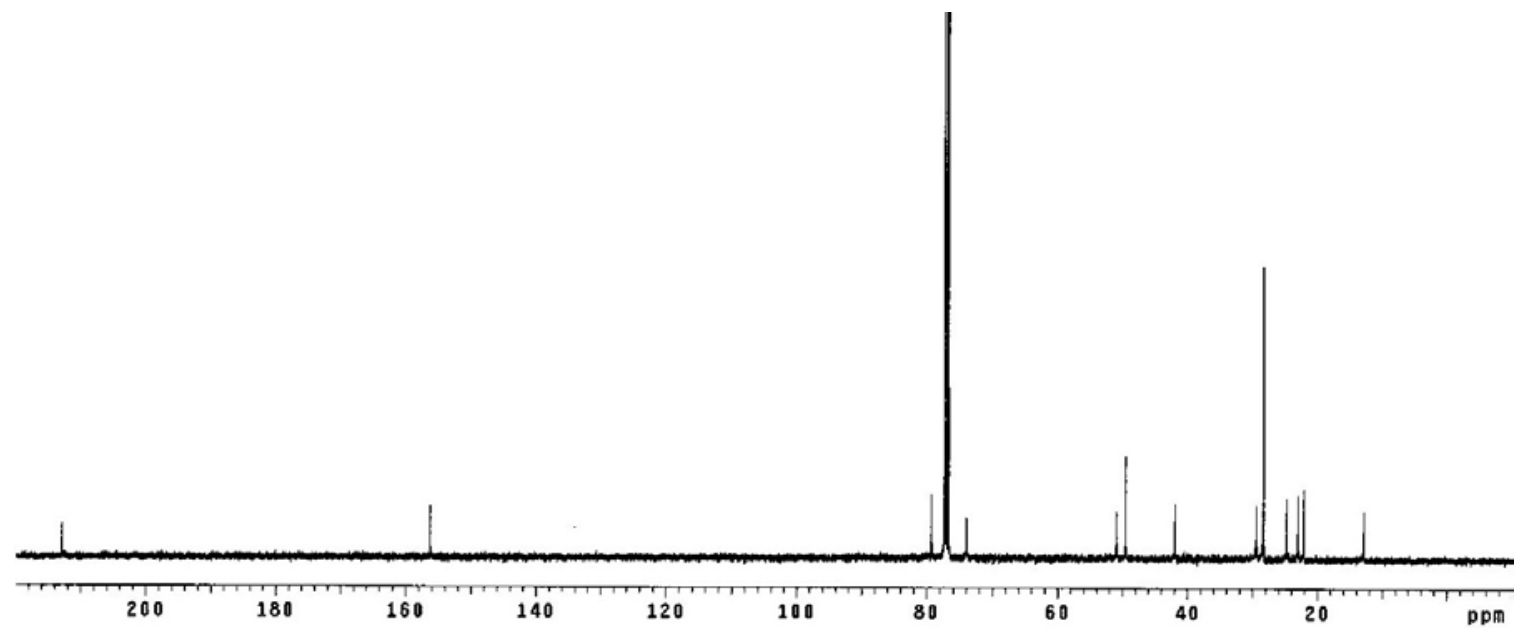


$(1 S, 2 R, 3 R)$-(2-Hydroxy-1-isobutyl-3-methyl-4-oxo-pentyl)-carbamic acid tert-butyl ester (iso-5b).<smiles>CC(=O)C(C)C(O)C(CC(C)C)NC(=O)OCc1ccccc1</smiles>

The title minor product was separated as a white solid. Crystallization from an etherhexane mixture provided $\boldsymbol{i s} \mathbf{o}-\mathbf{5 b}$ as thin needles.

$\underline{\text { TLC }}: \mathrm{R}_{f} 0.30$ (Hexane/EtOAc, 3/1).

${ }^{1}$ H NMR $\left(400 \mathrm{MHz}, \mathrm{CDCl}_{3}\right): \delta 4.33(\mathrm{~d}, J=9.0 \mathrm{~Hz}, 1 \mathrm{H}), 3.71-3.76(\mathrm{~m}, 1 \mathrm{H}), 3.58-3.64(\mathrm{~m}$, 1H), $3.12(\mathrm{br}, 1 \mathrm{H}), 2.73-2.77(\mathrm{~m}, 1 \mathrm{H}), 2.21(\mathrm{~s}, 3 \mathrm{H}), 1.60-1.70(\mathrm{~m}, 1 \mathrm{H}), 1.44(\mathrm{~s}, 9 \mathrm{H}), 1.24$ (d, $J=7.0 \mathrm{~Hz}, 3 \mathrm{H}), 1.19-1.24(\mathrm{~m}, 1 \mathrm{H}), 0.93$ (d, $J=6.5 \mathrm{~Hz}, 3 \mathrm{H}), 0.91-0.94(\mathrm{~m}, 1 \mathrm{H}), 0.91$ $(\mathrm{d}, J=6.1 \mathrm{~Hz}, 3 \mathrm{H})$.

${ }^{13} \mathbf{C ~ N M R}\left(100 \mathrm{MHz}, \mathrm{CDCl}_{3}\right): \delta 213.8,155.9,79.5,74.4,51.2,48.7,40.6,28.8,28.3$, 24.7, 23.8, 21.4, 11.0.

HRMS: Calcd [M+1] for $\mathrm{C}_{15} \mathrm{H}_{29} \mathrm{NO}_{4}$ : 288.2175; Found: 288.2182.

FTIR (film): 3350, 2967, 2875, 2100, 1686, 1525, 1459, 1378, 1311, 1272, 1237, 1176, $1124,1078,1035,1004,965,908,876 \mathrm{~cm}^{-1}$.

MP: $102-103{ }^{\circ} \mathrm{C}$.

$[\alpha]_{\mathbf{D}}=-11.8\left(\mathrm{c}=0.85, \mathrm{CHCl}_{3}\right)$. 
<smiles>CC(=O)OC(=O)N[C@@H](C[P+](=O)OCc1ccccc1)C(O)C(C)C(C)=O</smiles>

\section{${ }^{1}$ H NMR Spectrum}

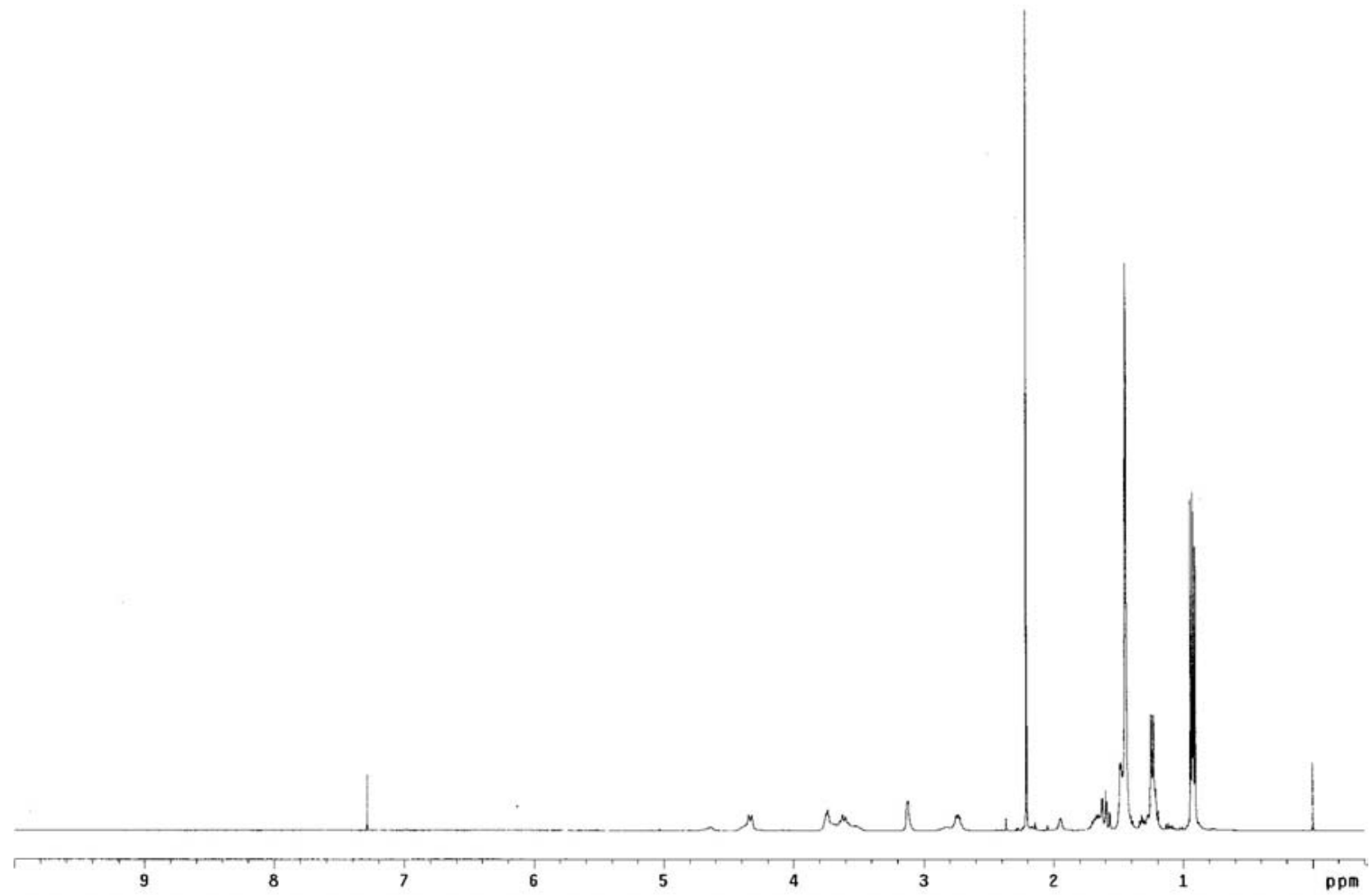

\section{${ }^{13}$ C NMR Spectrum}

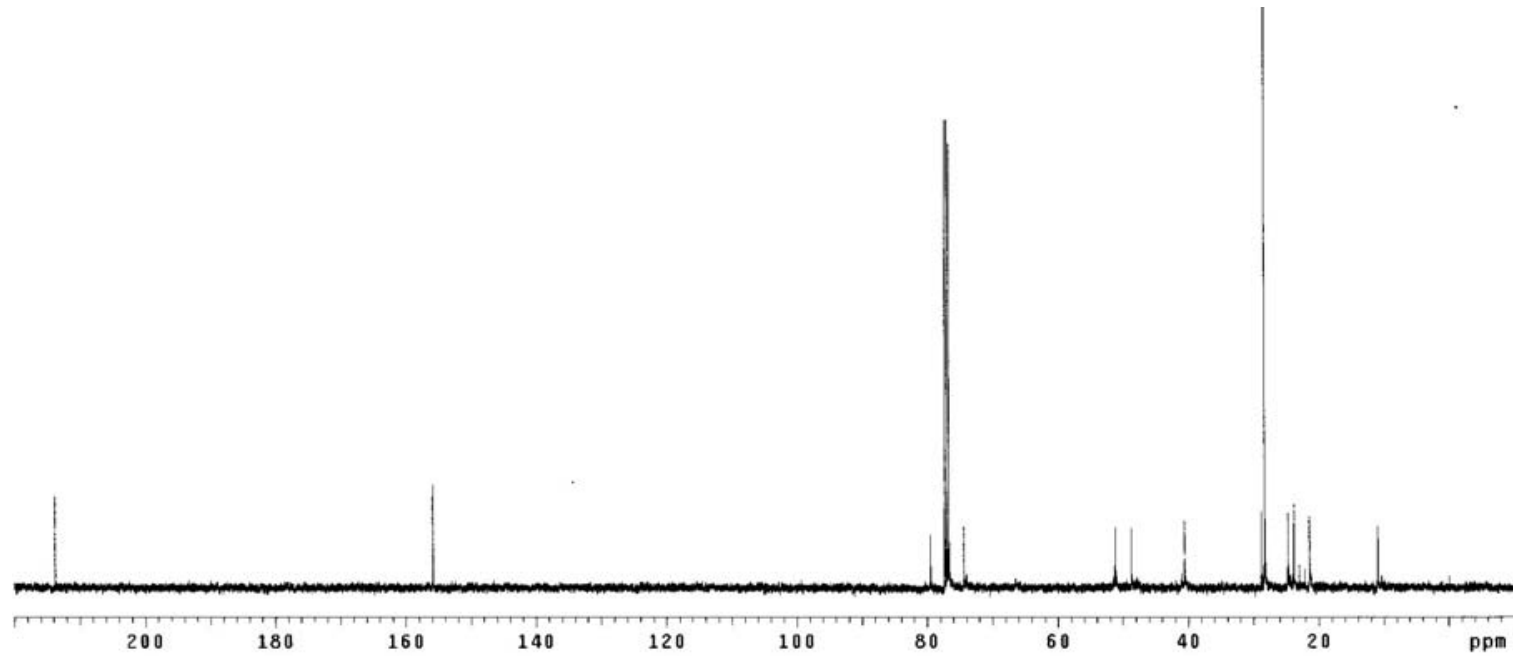



tert-butyl ester ( $N$-Me-iso-5b).<smiles>CC(=O)OC(C)(C)C[C@H](N)C(O)C(C)C(C)C(C)=O</smiles>

To a $13 \mathrm{~mm} \times 100 \mathrm{~mm}$ test-tube were added $\mathrm{Li}_{2} \mathrm{CO}_{3}(8.1 \mathrm{mg}, 10 \mathrm{~mol} \%)$, (2-furyl) 3 P (30.4 mg, $12 \mathrm{~mol} \%$ ), Rh(COD) $)_{2} \mathrm{OTf}(25.5 \mathrm{mg}, 5 \mathrm{~mol} \%$ ), $N$-Me- $N$-Boc-L-leucinal (244 mg, 100 $\mathrm{mol} \%)$ and dichloromethane $(1.1 \mathrm{~mL}, 1.0 \mathrm{M})$. Then the test-tube was sealed and the reaction system was purged with $\operatorname{Ar}(\mathrm{g})$ and $\mathrm{H}_{2}(\mathrm{~g})$ for 20 seconds each. The reaction system was placed under one atmosphere of hydrogen using a balloon and methyl vinyl ketone $(268 \mu \mathrm{L}, 300 \mathrm{~mol} \%)$ was added to the reaction mixture. The reaction mixture was allowed to stir at $25{ }^{\circ} \mathrm{C}$ for 16 hours. The title compound was purified by flash chromatography $\left(\mathrm{SiO}_{2}\right.$ : EtOAc/Hexane) to afford $60 \mathrm{mg}$ as colorless oil (18\% yield).

TLC $: \mathrm{R}_{f} 0.4$ (Hexane/EtOAc, 3/1).

${ }^{1}$ H NMR $(400 \mathrm{MHz}$, DMSO, complex mixture of rotomers): $\delta 4.80-5.01(\mathrm{~m}, 1 \mathrm{H}), 3.86-$ $4.08(\mathrm{~m}, 1 \mathrm{H}), 3.74-3.86(\mathrm{~m}, 1 \mathrm{H}), 3.52-3.74(\mathrm{~m}, 1 \mathrm{H}), 2.54-2.68(\mathrm{~m}, 3 \mathrm{H}), 2.32-2.40$ (m, $1 \mathrm{H}), 2.07-2.10(\mathrm{~m}, 3 \mathrm{H}), 1.42-1.49(\mathrm{~m}, 1 \mathrm{H}), 1.25-1.40(\mathrm{~m}, 10 \mathrm{H}), 0.93-1.00(\mathrm{~m}, 3 \mathrm{H}), 0.81-$ $0.91(\mathrm{~d}, 6 \mathrm{H})$.

${ }^{13} \mathbf{C}$ NMR $(100 \mathrm{MHz}, \mathrm{DMSO}$, complex mixture of rotomers): $\delta$ 200.1, 155.4, 155.0, 78.7, 78.5, 55.1, 50.1, 49.5, 49.1, 36.9, 29.4, 28.0, 27.5, 24.5, 24.3, 23.9, 21.4, 21.3, 9.4, 9.0.

HRMS: Calcd [M+1] for $\mathrm{C}_{16} \mathrm{H}_{31} \mathrm{NO}_{4}$ : 302.2331; Found: 302.2337.

FTIR (film): 3945, 3673, 3446, 3055, 2984, 2686, 2306, 1684, 1456, 1422, 1394, 1367 , $1326,1266,1152,1109,1048,984,897 \mathrm{~cm}^{-1}$.

$[\alpha]_{\mathrm{D}}=-31.6\left(\mathrm{c}=0.79, \mathrm{CHCl}_{3}\right)$. 
$\underbrace{\mathrm{OH} \mathrm{NCH}_{3} \mathrm{Boc}}_{\mathrm{CH}_{3}}$

${ }^{1}$ H NMR Spectrum

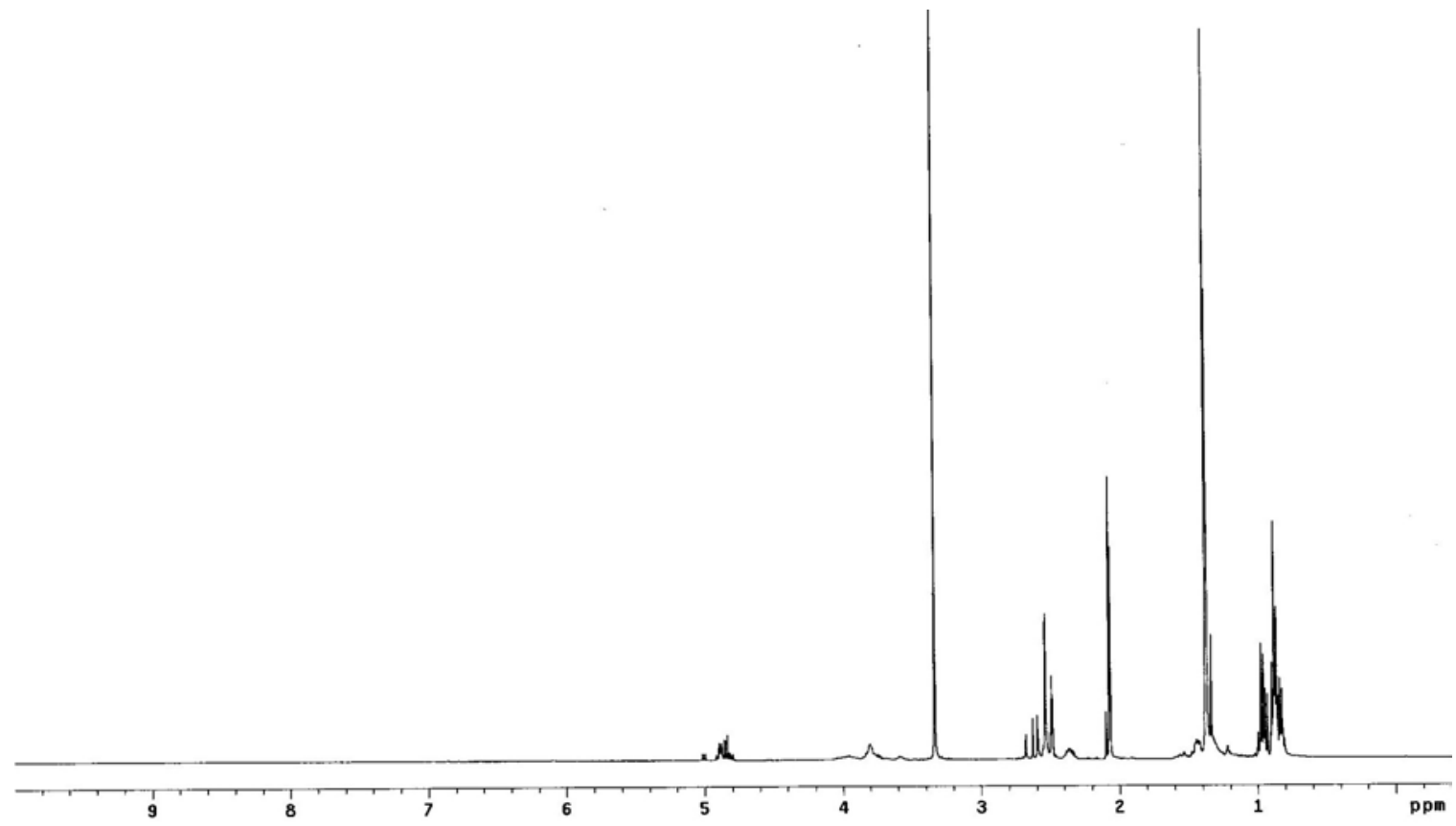

\section{${ }^{13}$ C NMR Spectrum}

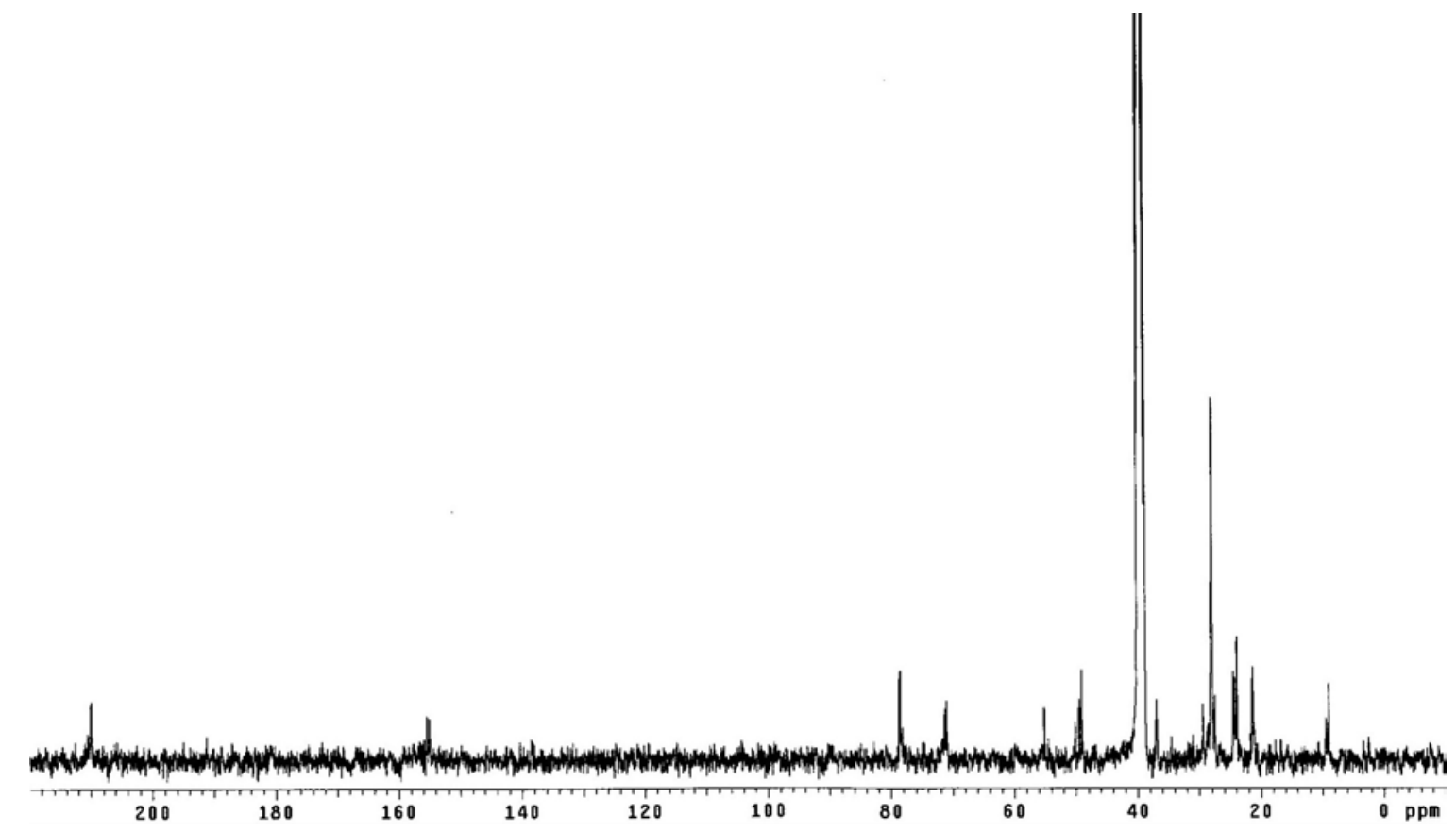


(1S,2S,3S)-(2-Hydroxy-1-isobutyl-3-methyl-4-oxo-hexyl)-carbamic acid tert-butyl ester (5c).<smiles>CCC(=O)OC(=O)N[C@@H](C[P+](=O)OC)[C@@H](O)[C@@H](C)C(=O)CC</smiles>

To a $13 \mathrm{~mm} \times 100 \mathrm{~mm}$ test-tube were added $\mathrm{Li}_{2} \mathrm{CO}_{3}(3.7 \mathrm{mg}, 10 \mathrm{~mol} \%$ ), (2-furyl) 3 P (14.1 $\mathrm{mg}, 12 \mathrm{~mol} \%)$, Rh(COD) $)_{2} \mathrm{OTf}$ (11.9 mg, $5 \mathrm{~mol} \%$ ), $N$-Boc-L-leucinal (110 mg, 100 $\mathrm{mol} \%)$ and dichloromethane $(0.51 \mathrm{~mL}, 1.0 \mathrm{M})$. Then the test-tube was sealed and the reaction system was purged with $\operatorname{Ar}(\mathrm{g})$ and $\mathrm{H}_{2}(\mathrm{~g})$ for 20 seconds each. The reaction system was placed under one atmosphere of hydrogen using a balloon and ethyl vinyl ketone $(125 \mu \mathrm{L}, 300 \mathrm{~mol} \%)$ was added to the reaction mixture. The reaction mixture was allowed to stir at $25{ }^{\circ} \mathrm{C}$ for 16 hours. The title compound was purified by flash chromatography $\left(\mathrm{SiO}_{2}\right.$ : EtOAc/Hexane) to afford $120 \mathrm{mg}$ as colorless oil (78 \% yield).

TLC : $\mathrm{R}_{f} 0.45$ (Hexane/EtOAc, 3/1).

프 NMR $\left(400 \mathrm{MHz}, \mathrm{CDCl}_{3}\right): \delta 4.67(\mathrm{~d}, J=9.6 \mathrm{~Hz}, 1 \mathrm{H}), 3.78-3.81(\mathrm{~m}, 1 \mathrm{H}), 3.56-3.62(\mathrm{~m}$, 1H), 2.80 (br, 1H), 2.73 (quintet, $J=7.2 \mathrm{~Hz}, 1 \mathrm{H}), 2.48-2.63(\mathrm{~m}, 2 \mathrm{H}), 1.58-1.68(\mathrm{~m}, 1 \mathrm{H})$, $1.44(\mathrm{~s}, 9 \mathrm{H}), 1.40-1.50(\mathrm{~m}, 1 \mathrm{H}), 1.26-1.35$ (m, 1H), 1.19 (d, $J=7.2 \mathrm{~Hz}, 3 \mathrm{H}), 1.05$ (t, $J=$ $7.2 \mathrm{~Hz}, 3 \mathrm{H}), 0.92(\mathrm{~d}, J=6.5 \mathrm{~Hz}, 3 \mathrm{H}), 0.91(\mathrm{~d}, J=6.5 \mathrm{~Hz}, 3 \mathrm{H})$.

${ }^{13} \mathbf{C ~ N M R}\left(100 \mathrm{MHz}, \mathrm{CDCl}_{3}\right): \delta 215.5,156.1,79.1,73.9,50.8,48.7,42.1,35.1,28.3$, 24.7, 22.9, 22.2, 13.2, 7.4 .

HRMS: Calcd [M+1] for $\mathrm{C}_{16} \mathrm{H}_{31} \mathrm{NO}_{4}$ : 302.2331; Found: 301.2334.

FTIR (film): 3440, 2961, 1711, 1564, 1502, 1453, 1367, 1250, 1170, 1109, 1021, 975, $867 \mathrm{~cm}^{-1}$.

$[\alpha]_{\mathrm{D}}=-26.2\left(\mathrm{c}=1.72, \mathrm{CHCl}_{3}\right)$. 
<smiles>CCC(=O)OC(=O)N[C@@H](C[P+](=O)OC)[C@@H](O)[C@@H](C)C(=O)CC</smiles>

\section{$\underline{ }{ }^{1}$ H NMR Spectrum}

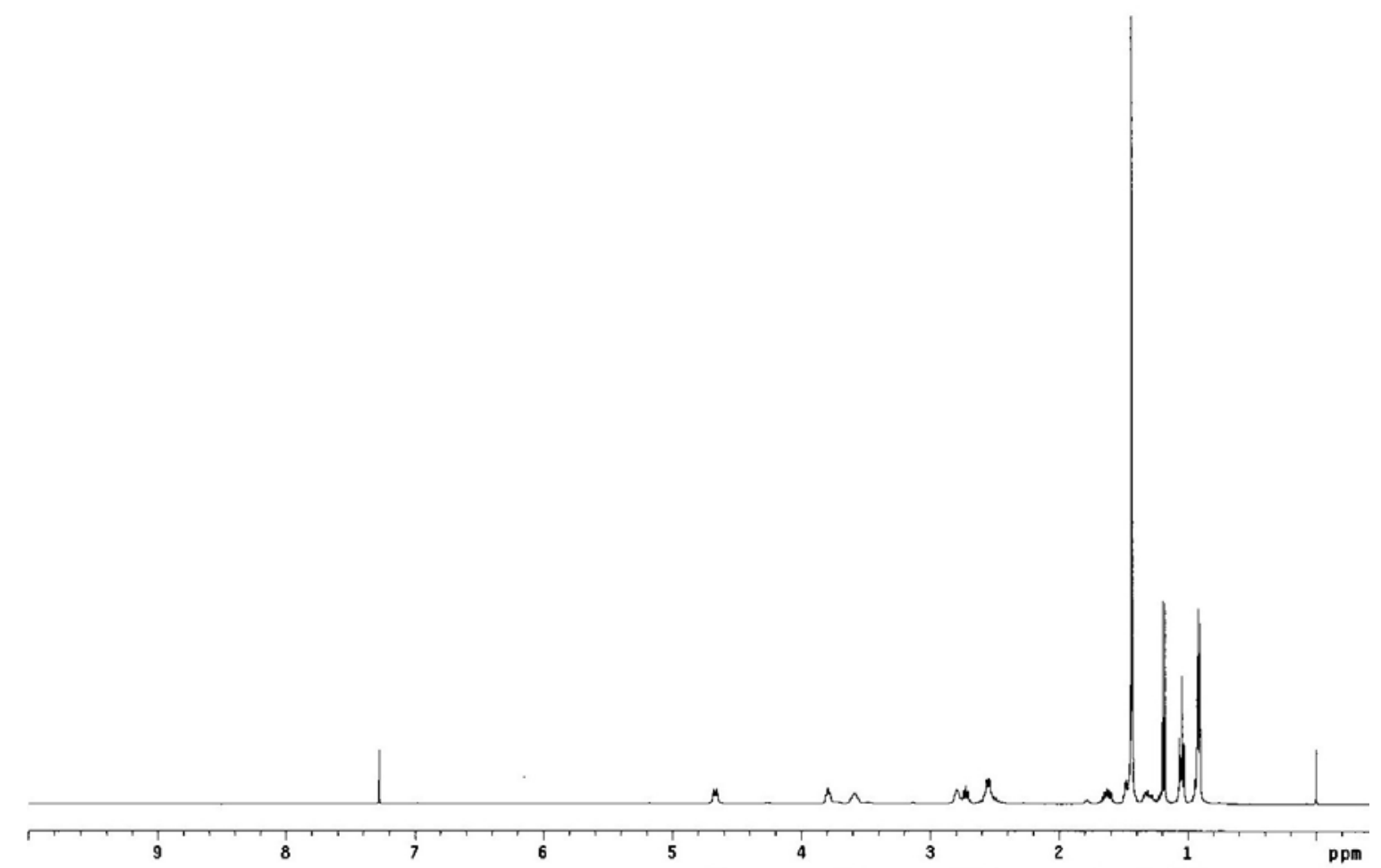

\section{${ }^{13}$ C NMR Spectrum}

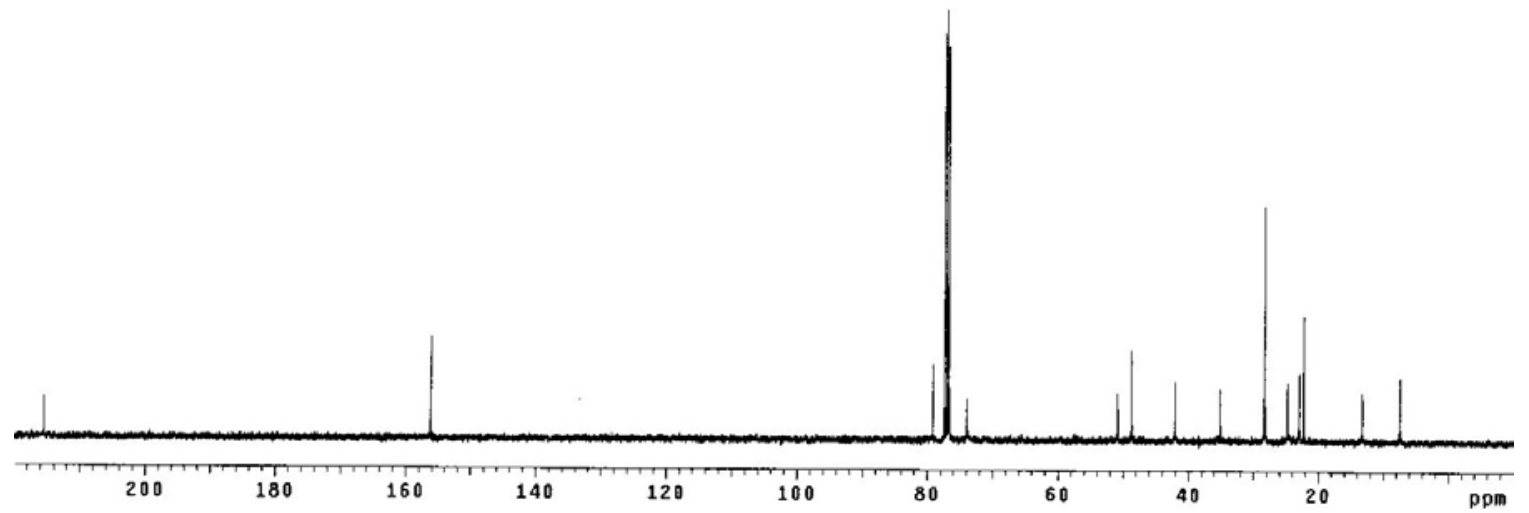


$(1 S, 2 S, 3 S)$-(1-Benzyl-2-hydroxy-3-methyl-4-oxo-pentyl)-carbamic acid tert-butyl ester (6b).<smiles>CC(=O)[C@H](C)[C@H](O)[C@H](Cc1ccccc1)NC(=O)O</smiles>

To a $13 \mathrm{~mm} \times 100 \mathrm{~mm}$ test-tube were added $\mathrm{Li}_{2} \mathrm{CO}_{3}(3.8 \mathrm{mg}, 10 \mathrm{~mol} \%$ ), (2-furyl) 3 P (14.2 mg, $12 \mathrm{~mol} \%$ ), Rh(COD) $)_{2} \mathrm{OTf}$ (11.9 mg, 5 mol\%), $N$-Boc-L-phenylalaninal (123 mg, 100 $\mathrm{mol} \%)$ and dichloromethane $(0.51 \mathrm{~mL}, 1.0 \mathrm{M})$. Then the test-tube was sealed and the reaction system was purged with $\operatorname{Ar}(\mathrm{g})$ and $\mathrm{H}_{2}(\mathrm{~g})$ for 20 seconds each. The reaction system was placed under one atmosphere of hydrogen using a balloon and methyl vinyl ketone $(125 \mu \mathrm{L}, 300 \mathrm{~mol} \%)$ was added to the reaction mixture. The reaction mixture was allowed to stir at $25{ }^{\circ} \mathrm{C}$ for 16 hours. The title compound was purified by flash chromatography $\left(\mathrm{SiO}_{2}\right.$ : EtOAc/Hexane) to afford $133 \mathrm{mg}$ of colorless oil (84 \% yield).

TLC $: \mathrm{R}_{f} 0.4$ (Hexane/EtOAc, 2/1).

${ }^{1} \mathbf{H}$ NMR $\left(400 \mathrm{MHz}, \mathrm{CDCl}_{3}\right): \delta 7.30-7.32(\mathrm{~m}, 2 \mathrm{H}), 7.19-7.21(\mathrm{~m}, 3 \mathrm{H}), 4.80(\mathrm{~d}, J=8.5 \mathrm{~Hz}$, 1H), 3.75-3.83 (m, 2H), 3.03 (br, 1H), 2.80-2.94 (m, 2H), 2.70 (quintet, $J=7.1 \mathrm{~Hz}, 1 \mathrm{H}$ ), $2.15(\mathrm{~s}, 3 \mathrm{H}), 1.39$ (s, 9H), $1.19(\mathrm{~d}, J=7.2 \mathrm{~Hz}, 3 \mathrm{H})$.

${ }^{13} \mathbf{C ~ N M R}\left(75 \mathrm{MHz}, \mathrm{CDCl}_{3}\right): \delta 213.1,156.1,138.1,129.2,128.4,126.5,79.5,72.3,54.1$, 49.8, 38.8, 29.3, 28.3, 12.8 .

HRMS: Calcd [M+1] for $\mathrm{C}_{18} \mathrm{H}_{27} \mathrm{NO}_{4}$ : 322.2018; Found: 322.2015.

FTIR (film): 3451, 2977, 2933, 2865, 2805, 2606, 1961, 1714, 1494, 1445, 1383, 1351, $1296,1248,1153,1121,1076,1043,934,845 \mathrm{~cm}^{-1}$.

$[\alpha]_{\mathrm{D}}=-29.0\left(\mathrm{c}=2.07, \mathrm{CHCl}_{3}, 94 \%\right.$ ee $)$. 
<smiles>CC(=O)[C@H](C)[C@@H](O)[C@H](Cc1ccccc1)NC(=O)OCc1ccccc1</smiles>

\section{${ }^{1}$ H NMR Spectrum}

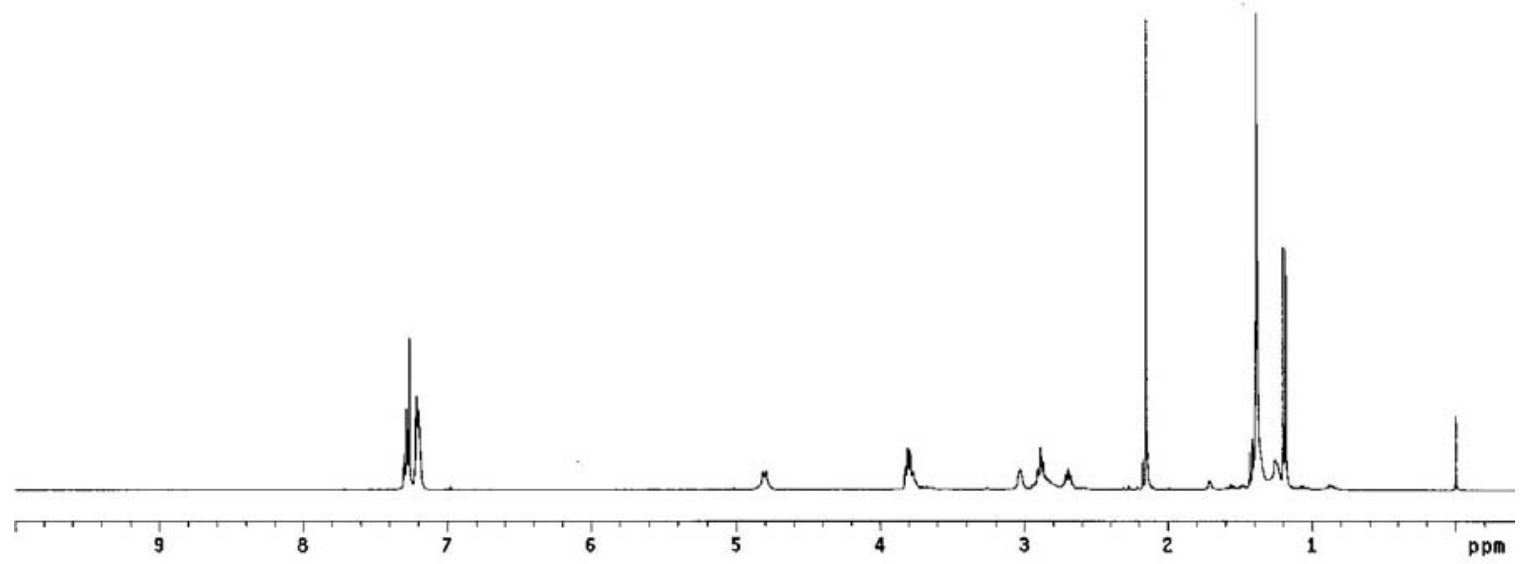

${ }^{13}$ C NMR Spectrum

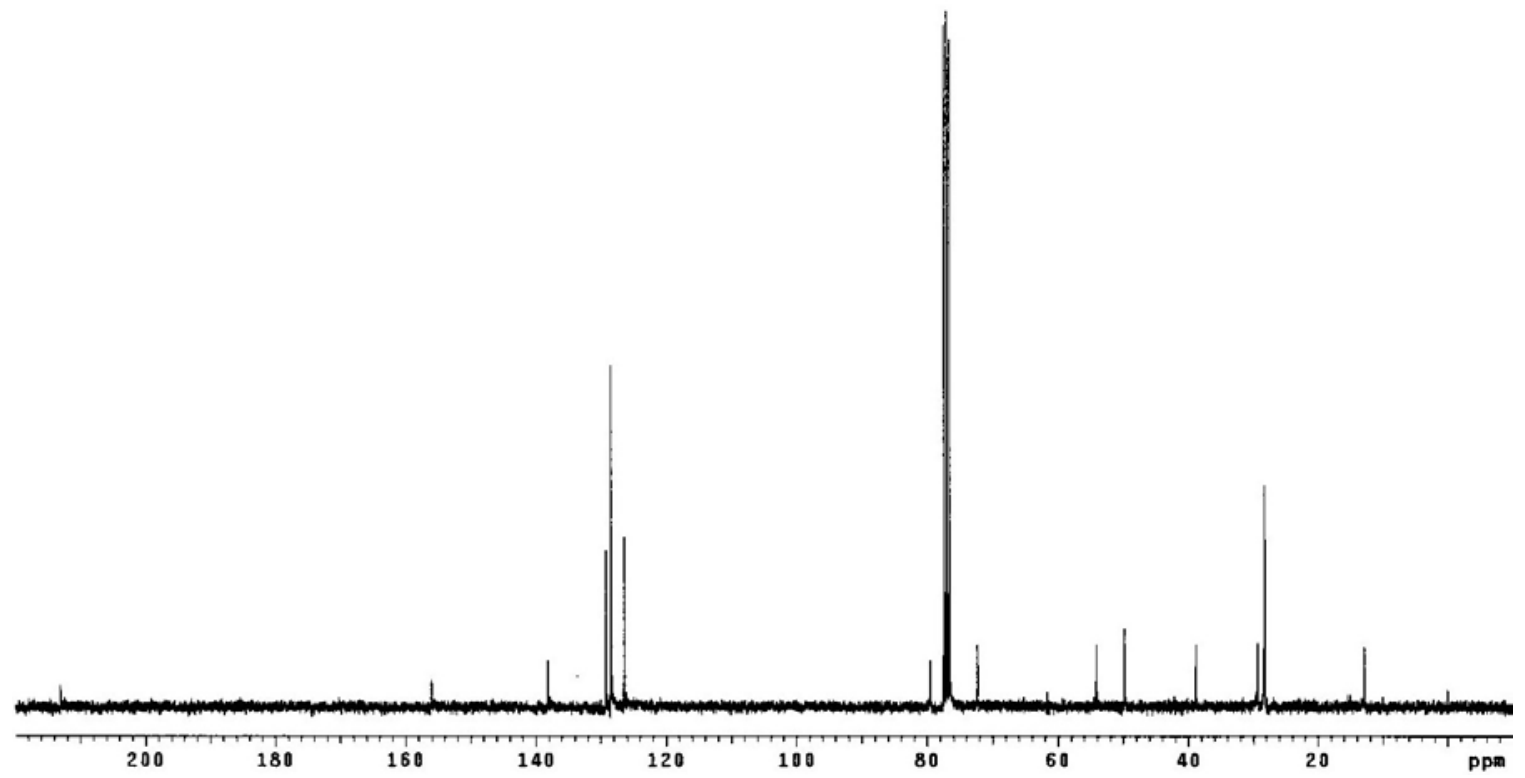


<smiles>CC(=O)[C@H](C)[C@H](O)[C@H](Cc1ccccc1)NC(=O)O</smiles>

\section{$\underline{\text { HPLC }}$}

6a-racemic: $\mathrm{t}_{1}=9.7 \mathrm{~min}, \mathrm{t}_{2}=11.0 \mathrm{~min}($ Chiralpak AD-H column $-4.6 \times 250 \mathrm{~mm}$, $i \mathrm{PrOH} /$ Hexane $=5 / 95,1 \mathrm{~mL} / \mathrm{min}, 254 \mathrm{~nm})$.

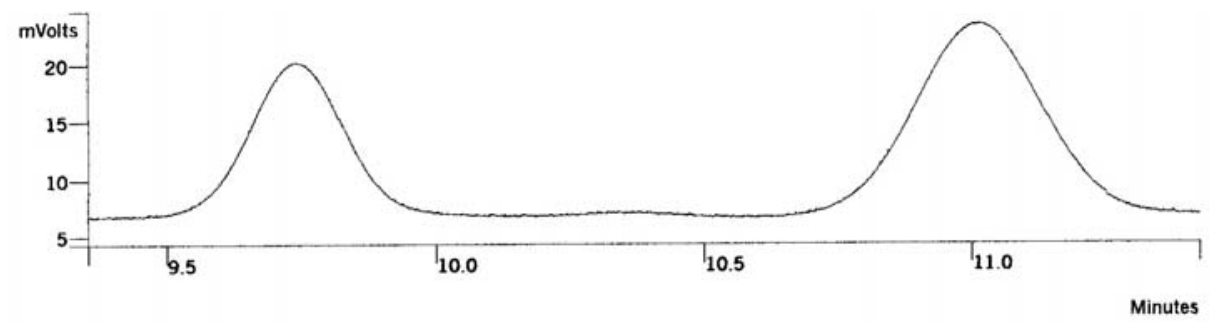

6a-chiral: $\mathrm{t}_{\text {major }}=11.0 \mathrm{~min}, \mathrm{t}_{\text {minor }}=9.8 \mathrm{~min}$, ee $=94 \%$.

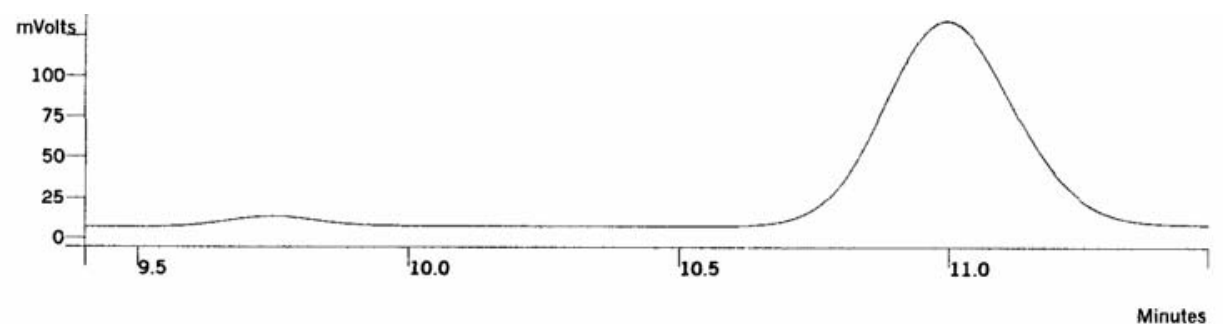

6b-racemic: $\mathrm{t}_{\text {major- } 1}=6.5 \mathrm{~min}, \mathrm{t}_{\text {major-2 }}=7.8 \mathrm{~min}, \mathrm{t}_{\text {minor- } 1}=5.5 \mathrm{~min}, \mathrm{t}_{\text {minor- } 2}=6.0 \mathrm{~min}, \mathrm{dr}=$ 20:1 (Chiralcel OJ-H column - $4.6 \times 250 \mathrm{~mm}, i \mathrm{PrOH} / \mathrm{Hexane}=5 / 95,1 \mathrm{~mL} / \mathrm{min}, 254 \mathrm{~nm})$.

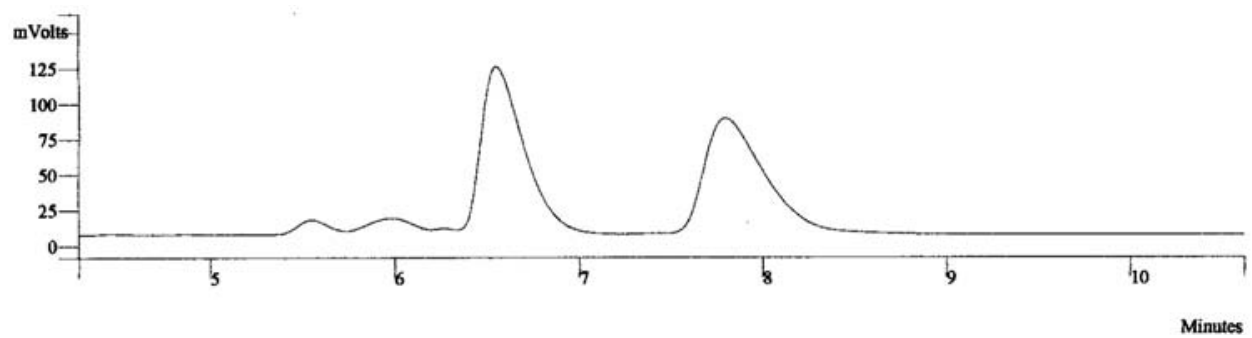

6b-chiral: $\mathrm{t}_{\text {major }}=6.6 \mathrm{~min}, \mathrm{t}_{\text {minor }}=8.1 \mathrm{~min}$, ee $=94 \%$.

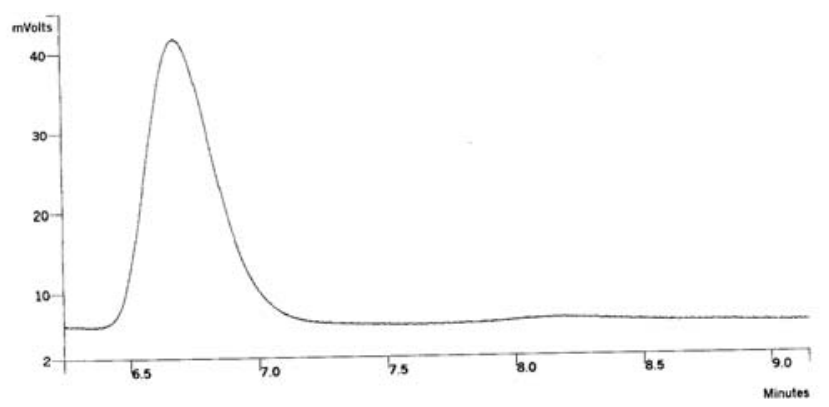




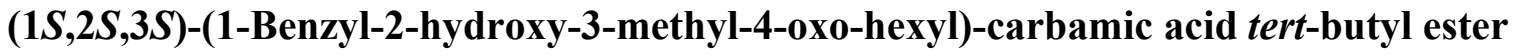

(6c).<smiles>CCC(=O)C(C)[C@H](O)[C@H](Cc1ccccc1)N[R6](=O)[O-]</smiles>

To a $13 \mathrm{~mm} \times 100 \mathrm{~mm}$ test-tube were added $\mathrm{Li}_{2} \mathrm{CO}_{3}(3.8 \mathrm{mg}, 10 \mathrm{~mol} \%$ ), (2-furyl) 3 P (14.2 mg, $12 \mathrm{~mol} \%$ ), Rh(COD) $)_{2} \mathrm{OTf}$ (11.9 mg, 5 mol\%), $N$-Boc-L-phenylalaninal (123 mg, 100 $\mathrm{mol} \%)$ and dichloromethane $(0.51 \mathrm{~mL}, 1.0 \mathrm{M})$. Then the test-tube was sealed and the reaction system was purged with $\operatorname{Ar}(\mathrm{g})$ and $\mathrm{H}_{2}(\mathrm{~g})$ for 20 seconds each. The reaction system was placed under one atmosphere of hydrogen using a balloon and ethyl vinyl ketone $(152 \mu \mathrm{L}, 300 \mathrm{~mol} \%)$ was added to the reaction mixture. The reaction mixture was allowed to stir at $25{ }^{\circ} \mathrm{C}$ for 16 hours. The title compound was purified by flash chromatography $\left(\mathrm{SiO}_{2}\right.$ : EtOAc/Hexane) to afford $154 \mathrm{mg}$ of colorless oil (93\% yield).

TLC : $\mathrm{R}_{f} 0.55$ (Hexane/EtOAc, 2/1).

1H NMR $\left(400 \mathrm{MHz}, \mathrm{CDCl}_{3}\right): \delta 7.26-7.30(\mathrm{~m}, 2 \mathrm{H}), 7.18-7.23(\mathrm{~m}, 3 \mathrm{H}), 4.79(\mathrm{~d}, J=9.2 \mathrm{~Hz}$, $1 \mathrm{H}), 3.79-3.83(\mathrm{~m}, 1 \mathrm{H}), 3.72-3.78(\mathrm{~m}, 1 \mathrm{H}), 3.07$ (br, 1H), 2.95-2.83 (m, 2H), 2.83 (br, $1 \mathrm{H}), 2.71$ (quintet, $J=7.2 \mathrm{~Hz}, 1 \mathrm{H}), 2.38-2.61(\mathrm{~m}, 2 \mathrm{H}), 1.38(\mathrm{~s}, 9 \mathrm{H}), 1.17(\mathrm{~d}, J=7.2 \mathrm{~Hz}$, $3 \mathrm{H}), 1.01$ ( $\mathrm{t}, J=7.2 \mathrm{~Hz}, 3 \mathrm{H})$.

${ }^{13} \mathbf{C ~ N M R}\left(100 \mathrm{MHz}, \mathrm{CDCl}_{3}\right): \delta 215.7,156.0,138.2,129.2,128.4,126.3,79.5,72.5,65.8$, $54.0,48.9,39.0,35.1,28.3,15.2,13.2,7.5$.

HRMS: Calcd [M+1] for $\mathrm{C}_{19} \mathrm{H}_{29} \mathrm{NO}_{4}$ : 336.2175; Found: 336.2175.

FTIR (film): 3432, 3055, 2980, 2937, 1704, 1499, 1456, 1392, 1367, 1266, 1169, 1080, $1023,976,895 \mathrm{~cm}^{-1}$.

$[\alpha]_{\mathrm{D}}=-30.9\left(\mathrm{c}=1.78, \mathrm{CHCl}_{3}\right)$. 
<smiles>CCC(=O)OC(=O)N[C@@H](Cc1ccccc1)[C@@H](O)[C@@H](C)C(=O)OCc1ccccc1</smiles>

\section{${ }^{1}$ H NMR Spectrum}

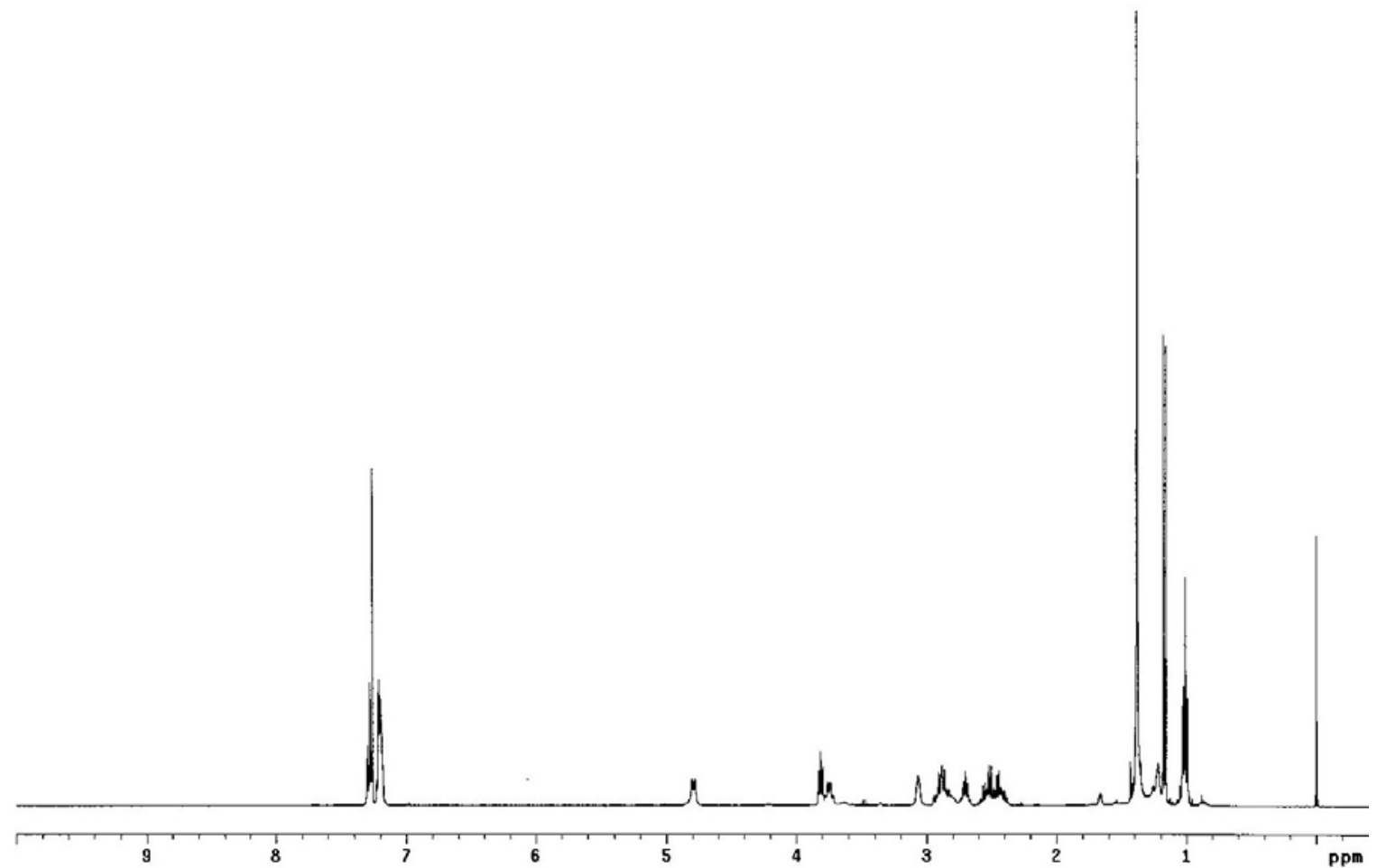

\section{${ }^{13}$ C NMR Spectrum}

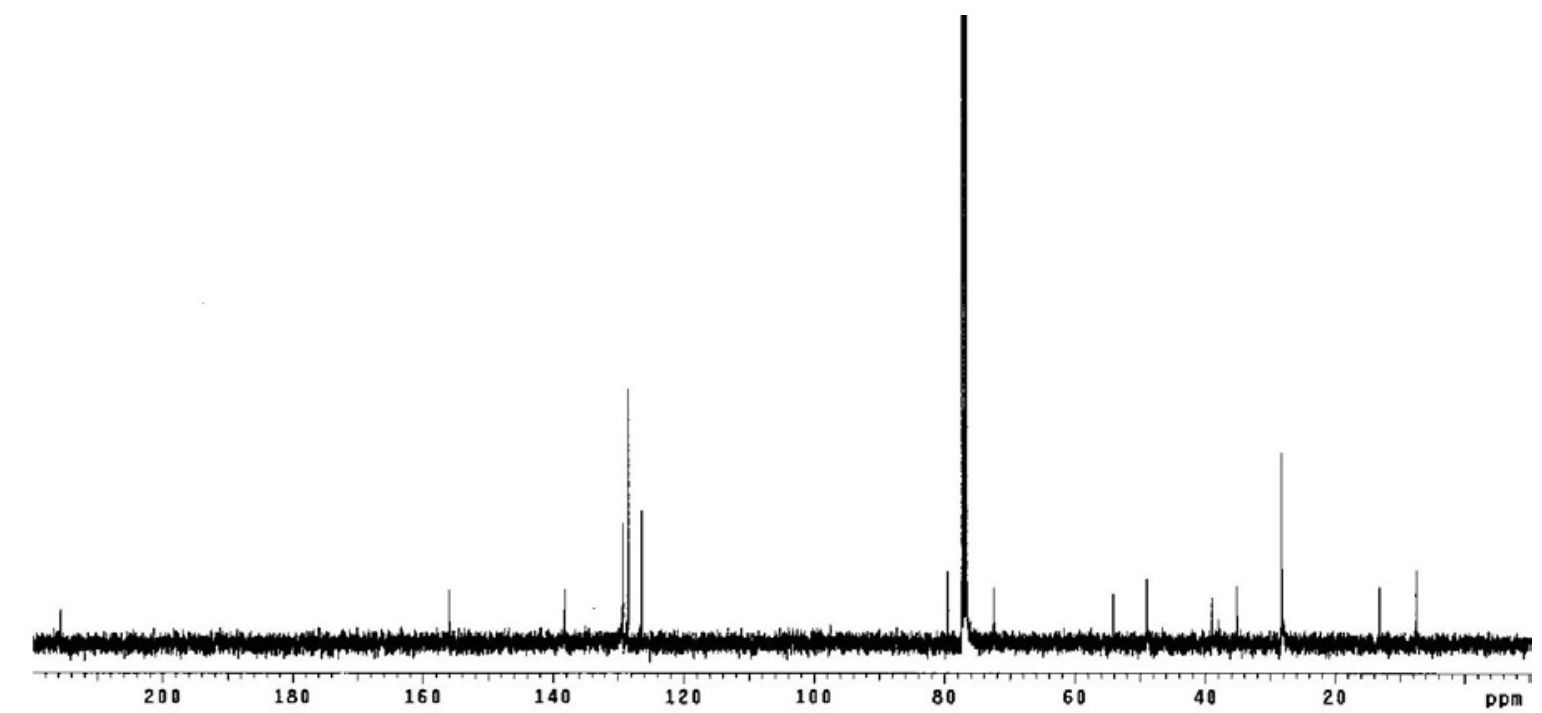




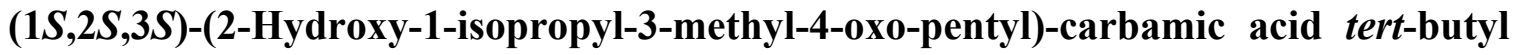
ester (7b).

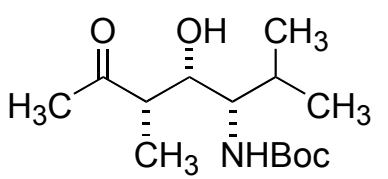

To a $13 \mathrm{~mm} \times 100 \mathrm{~mm}$ test-tube were added $\mathrm{Li}_{2} \mathrm{CO}_{3}$ (4.1 mg, $10 \mathrm{~mol} \%$ ), (2-furyl) 3 P (15.4 mg, $12 \mathrm{~mol} \%$ ), Rh(COD) $)_{2} \mathrm{OTf}(12.9 \mathrm{mg}, 5 \mathrm{~mol} \%$ ), $N$-Boc-L-valinal (111 mg, $100 \mathrm{~mol} \%$ ) and dichloromethane $(0.55 \mathrm{~mL}, 1.0 \mathrm{M})$. Then the test-tube was sealed and the reaction system was purged with $\mathrm{Ar}(\mathrm{g})$ and $\mathrm{H}_{2}(\mathrm{~g})$ for 20 seconds each. The reaction system was placed under one atmosphere of hydrogen using a balloon and methyl vinyl ketone (125 $\mu \mathrm{L}, 300 \mathrm{~mol} \%$ ) was added to the reaction mixture. The reaction mixture was allowed to stir at $25{ }^{\circ} \mathrm{C}$ for 16 hours. The title compound was purified by flash chromatography $\left(\mathrm{SiO}_{2}:\right.$ EtOAc/Hexane) to afford $87 \mathrm{mg}$ of white soild (58\% yield). Crystallization from an ether-hexane mixture provides $\mathbf{7 b}$ as clear needles.

TLC $: \mathrm{R}_{f} 0.6$ (Hexane/EtOAc, 2/1).

$\underline{{ }^{1} \mathbf{H} \text { NMR }}\left(400 \mathrm{MHz}, \mathrm{CDCl}_{3}\right): \delta 4.78(\mathrm{~d}, J=9.2 \mathrm{~Hz}, 1 \mathrm{H}), 3.99-4.03(\mathrm{~m}, 1 \mathrm{H}), 3.17-3.22(\mathrm{~m}$, $1 \mathrm{H}), 2.66-2.73(\mathrm{~m}, 2 \mathrm{H}), 2.20$ (s, 3H), 1.81-1.89 (m, 1H), 1.45 (s, 9H), 1.20 (d, J=7.2 Hz, $3 \mathrm{H}), 0.97(\mathrm{~d}, J=6.8 \mathrm{~Hz}, 3 \mathrm{H}), 0.92(\mathrm{~d}, J=6.8 \mathrm{~Hz}, 3 \mathrm{H})$.

${ }^{13} \mathbf{C ~ N M R}\left(75 \mathrm{MHz}, \mathrm{CDCl}_{3}\right): \delta 213.2,156.5,79.2,71.3,58.2,57.3,49.9,38.4,30.3,29.5$, 28.3, 19.7, 19.0, 12.8 .

HRMS: Calcd [M+1] for $\mathrm{C}_{14} \mathrm{H}_{27} \mathrm{NO}_{4}$ : 274.2018; Found: 274.2019.

FTIR (film): 3436, 3054, 2985, 2685, 2410, 2305, 1707, 1606, 1549, 1501, 1422, 1367 , $1265,1170,896 \mathrm{~cm}^{-1}$.

MP: $120-121^{\circ} \mathrm{C}$.

$[\alpha]_{\mathrm{D}}=-16.4\left(\mathrm{c}=1.22, \mathrm{CHCl}_{3}\right)$. 
<smiles>CC(=O)OC(=O)N[C@@H](C(C)C)[C@H](O)[C@H](C)C(C)=O</smiles>

\section{${ }^{1}$ H NMR Spectrum}

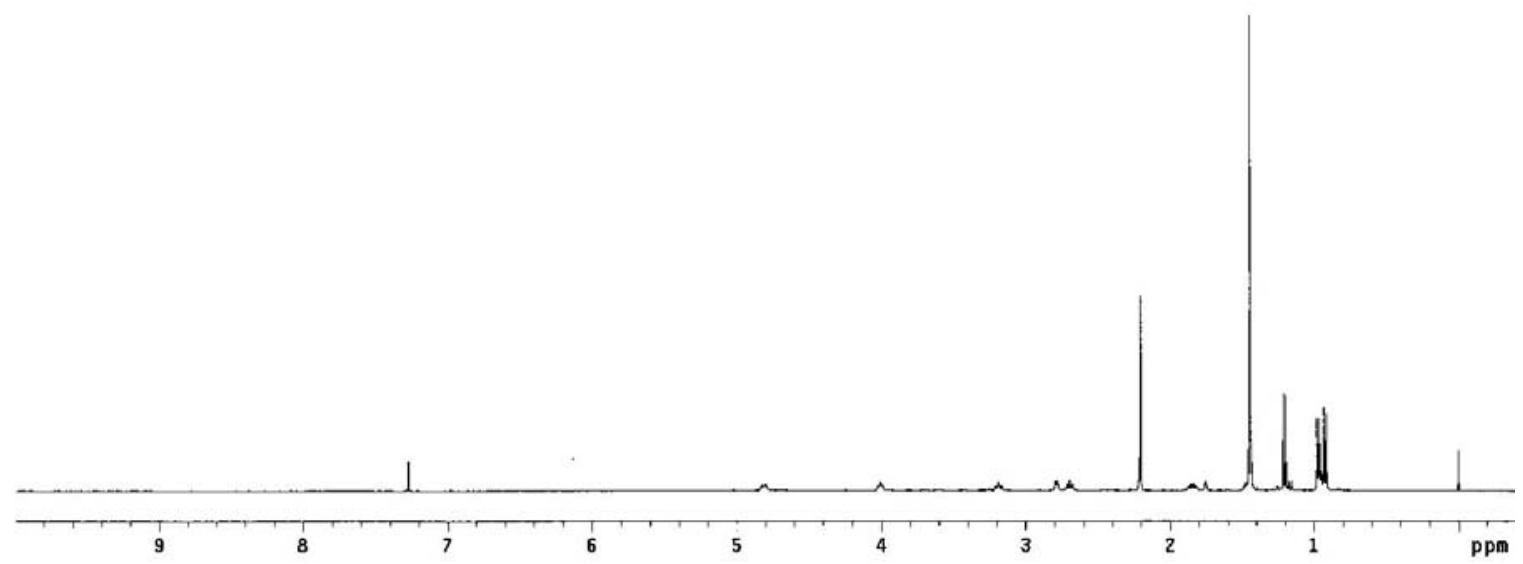

\section{${ }^{13}$ C NMR Spectrum}

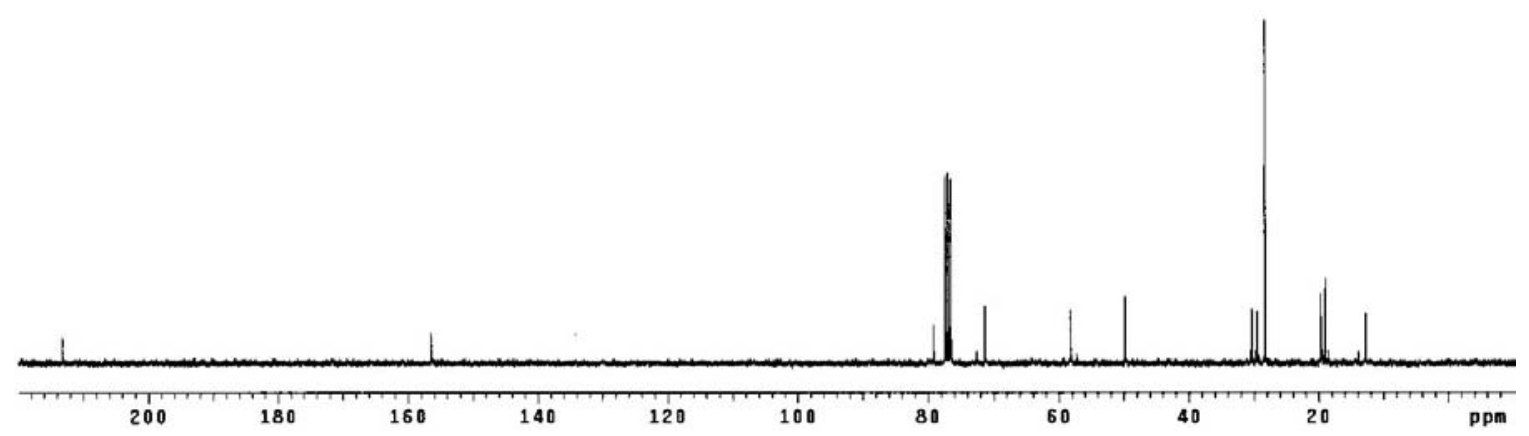




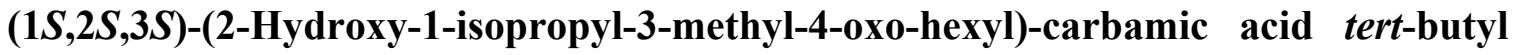
ester (7c).<smiles>CCC(=O)C(C)[C@H](O)[C@H](NC(=O)OC(C)(C)C)C(C)C</smiles>

To a $13 \mathrm{~mm} \times 100 \mathrm{~mm}$ test-tube were added $\mathrm{Li}_{2} \mathrm{CO}_{3}(3.8 \mathrm{mg}, 10 \mathrm{~mol} \%$ ), (2-furyl) 3 P (14.3 mg, $12 \mathrm{~mol} \%$ ), Rh(COD) $)_{2} \mathrm{OTf}(12.0 \mathrm{mg}, 5 \mathrm{~mol} \%$ ), $N$-Boc-L-valinal (104 mg, $100 \mathrm{~mol} \%$ ) and dichloromethane $(0.51 \mathrm{~mL}, 1.0 \mathrm{M})$. Then the test-tube was sealed and the reaction system was purged with $\mathrm{Ar}(\mathrm{g})$ and $\mathrm{H}_{2}(\mathrm{~g})$ for 20 seconds each. The reaction system was placed under one atmosphere of hydrogen using a balloon and ethyl vinyl ketone $(153 \mu \mathrm{L}$, $300 \mathrm{~mol} \%$ ) was added to the reaction mixture. The reaction mixture was allowed to stir at $25{ }^{\circ} \mathrm{C}$ for 16 hours. The title compound was purified by flash chromatography $\left(\mathrm{SiO}_{2}\right.$ : EtOAc/Hexane) to afford $82 \mathrm{mg}$ of white soild (56\% yield).

TLC : $\mathrm{R}_{f} 0.65$ (Hexane/EtOAc, 2/1).

1H NMR $\left(400 \mathrm{MHz}, \mathrm{CDCl}_{3}\right): \delta 4.80(\mathrm{~d}, J=9.2 \mathrm{~Hz}, 1 \mathrm{H}), 4.00-4.03(\mathrm{~m}, 1 \mathrm{H}), 3.13-3.18(\mathrm{~m}$, 1H), 2.76 (br, 1H), 2.71 (quintet, $J=7.2 \mathrm{~Hz}, 1 \mathrm{H}), 2.44-2.61(\mathrm{~m}, 2 \mathrm{H}), 1.80-1.89(\mathrm{~m}, 1 \mathrm{H})$, $1.44(\mathrm{~s}, 9 \mathrm{H}), 1.18(\mathrm{~d}, J=7.2 \mathrm{~Hz}, 3 \mathrm{H}), 1.04$ (t, $J=7.2 \mathrm{~Hz}, 3 \mathrm{H}), 0.97$ (d, $J=6.8 \mathrm{~Hz}, 3 \mathrm{H})$, $0.92(\mathrm{~d}, J=6.8 \mathrm{~Hz}, 3 \mathrm{H})$.

${ }^{13} \mathbf{C ~ N M R}\left(100 \mathrm{MHz}, \mathrm{CDCl}_{3}\right): \delta 215.8,156.5,79.2,71.5,58.2,49.1,35.2,30.6,28.3$, 19.7. 19.0. 13.0. 7.5 .

HRMS: Calcd [M+1] for $\mathrm{C}_{15} \mathrm{H}_{29} \mathrm{NO}_{4}$ : 288.2175; Found: 288.2173.

FTIR (film): 3436, 3055, 2978, 2877, 2409, 2348, 1703, 1502, 1461, 1391, 1367, 1266, $1171,1021,975,895 \mathrm{~cm}^{-1}$.

MP: $96-98^{\circ} \mathrm{C}$.

$[\alpha]_{\mathrm{D}}=-10.8\left(\mathrm{c}=1.39, \mathrm{CHCl}_{3}\right)$. 
<smiles></smiles>

\section{$\underline{ }{ }^{1}$ H NMR Spectrum}

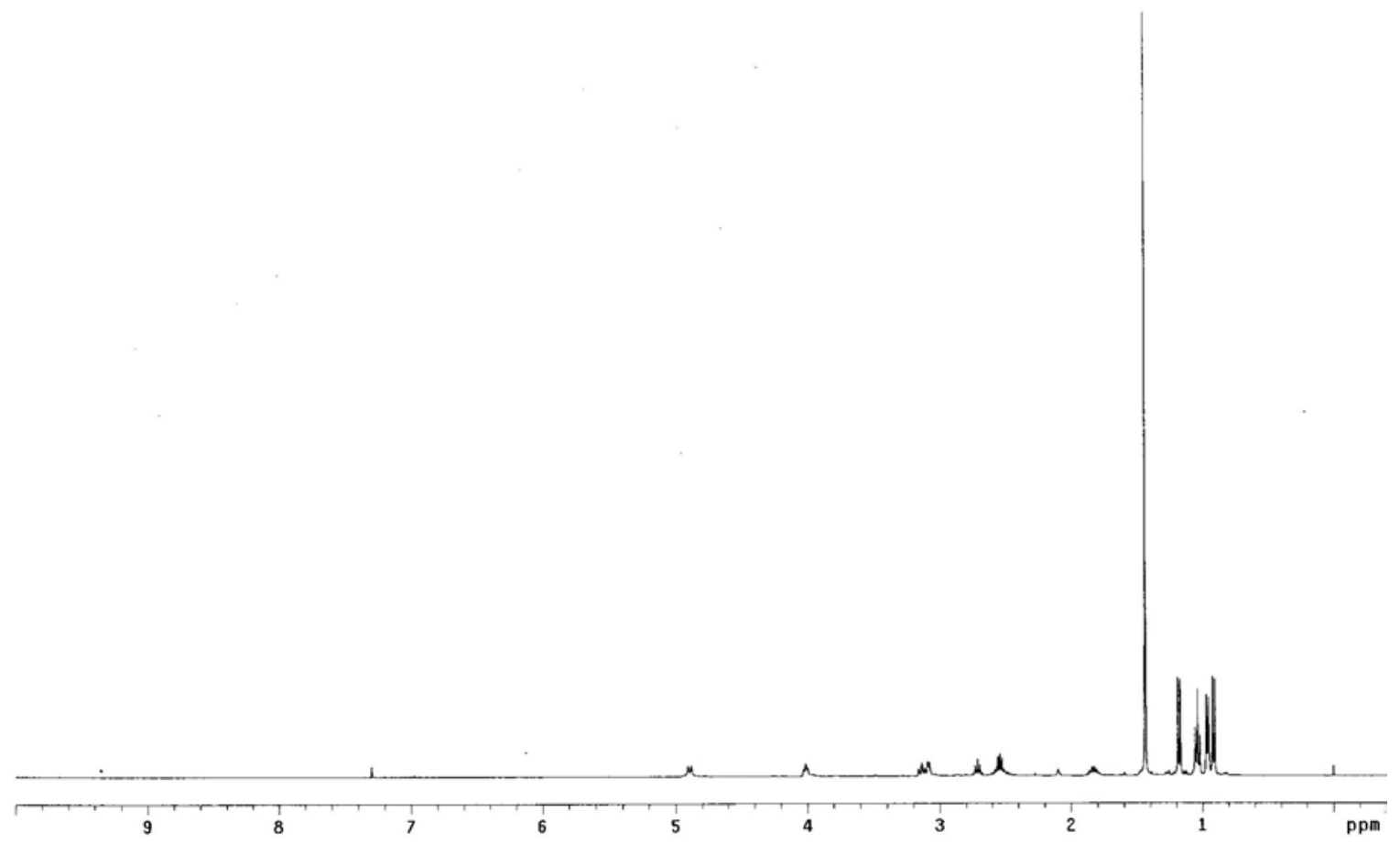

\section{${ }^{13}$ C NMR Spectrum}

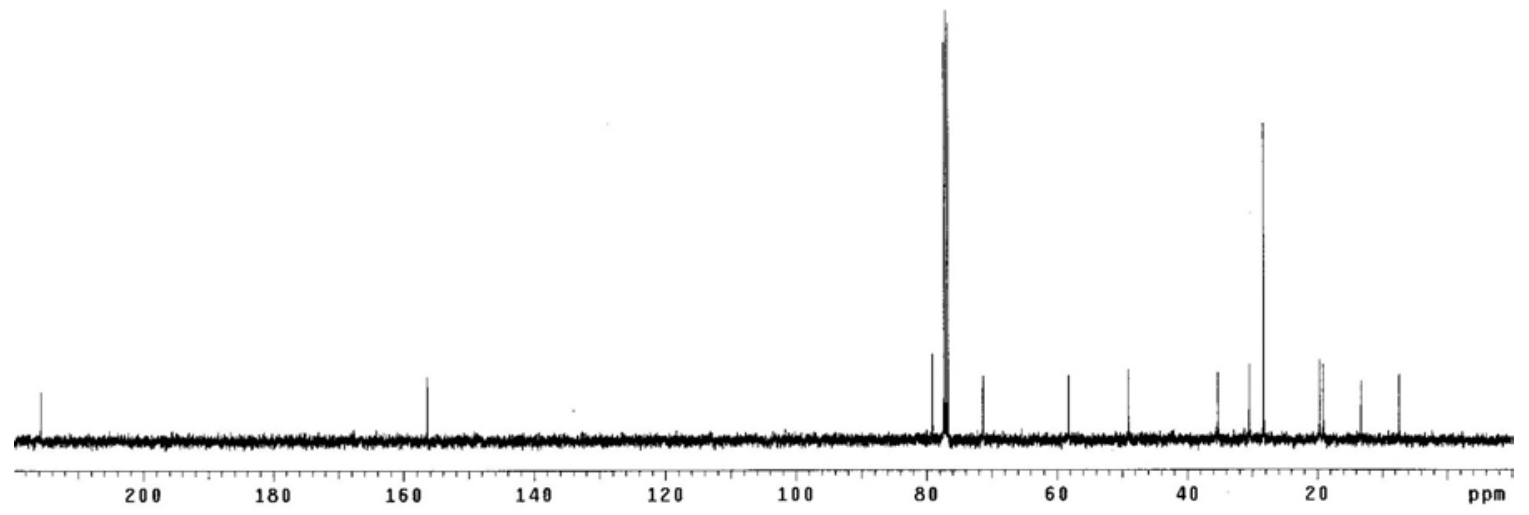




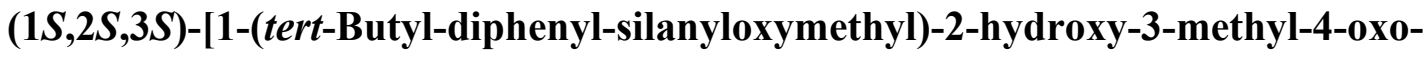
pentyl]-carbamic acid tert-butyl ester (8b).<smiles>CC(=O)[C@H](C)[C@@H](O)[C@@H](N)CO[PbH3]</smiles>

To a $13 \mathrm{~mm} \times 100 \mathrm{~mm}$ test-tube were added $\mathrm{Li}_{2} \mathrm{CO}_{3}(3.3 \mathrm{mg}, 10 \mathrm{~mol} \%$ ), (2-furyl) 3 P (12.3 mg, $12 \mathrm{~mol} \%$ ), $\mathrm{Rh}(\mathrm{COD})_{2} \mathrm{OTf}(10.3 \mathrm{mg}, 5 \mathrm{~mol} \%$ ), $N$-Boc-O-TBDPS- L-serinal (188 mg, $100 \mathrm{~mol} \%)$ and dichloromethane $(0.44 \mathrm{~mL}, 1.0 \mathrm{M})$. Then the test-tube was sealed and the reaction system was purged with $\operatorname{Ar}(\mathrm{g})$ and $\mathrm{H}_{2}(\mathrm{~g})$ for 20 seconds each. The reaction system was placed under one atmosphere of hydrogen using a balloon and methyl vinyl ketone (108 $\mu \mathrm{L}, 300 \mathrm{~mol} \%)$ was added to the reaction mixture. The reaction mixture was allowed to stir at $25{ }^{\circ} \mathrm{C}$ for 16 hours. The title compound was purified by flash chromatography $\left(\mathrm{SiO}_{2}\right.$ : EtOAc/Hexane) to afford $181 \mathrm{mg}$ of colorless oil (83\% yield).

TLC $: \mathrm{R}_{f} 0.5$ (Hexane/EtOAc, 2/1).

프 NMR $\left(400 \mathrm{MHz}, \mathrm{CDCl}_{3}\right): \delta 7.63-7.68(\mathrm{~m}, 4 \mathrm{H}), 7.37-7.47(\mathrm{~m}, 6 \mathrm{H}), 5.11(\mathrm{~d}, J=9.2 \mathrm{~Hz}$, $1 \mathrm{H}), 4.14-4.17(\mathrm{~m}, 1 \mathrm{H}), 3.84\left(\mathrm{dd}, \mathrm{A}\right.$ of $\left.\mathrm{ABX}, J_{A B}=10.6 \mathrm{~Hz}, J_{A X}=3.8 \mathrm{~Hz}, 1 \mathrm{H}\right), 3.78(\mathrm{dd}$, $\mathrm{B}$ of $\left.\mathrm{ABX}, J_{A B}=10.6 \mathrm{~Hz}, J_{B X}=4.1 \mathrm{~Hz}, 1 \mathrm{H}\right), 3.65-3.67(\mathrm{~m}, 1 \mathrm{H}), 3.26(\mathrm{~d}, J=2.7 \mathrm{~Hz}, 1 \mathrm{H})$, 2.72 (quintet, $J=7.2 \mathrm{~Hz}, 1 \mathrm{H}), 2.18(\mathrm{~s}, 3 \mathrm{H}), 1.44(\mathrm{~s}, 9 \mathrm{H}), 1.20$ (d, $J=6.8 \mathrm{~Hz}, 3 \mathrm{H}), 1.07$ (s, 9H).

${ }^{13} \mathbf{C ~ N M R}\left(100 \mathrm{MHz}, \mathrm{CDCl}_{3}\right): \delta 211.9,155.9,135.5,135.5,132.4,130.0,127.9,79.4,2.9$, $66.7,52.4,49.2,29.5,28.3,26.8,19.1,12.9$.

HRMS: Calcd [M+1] for $\mathrm{C}_{28} \mathrm{H}_{41} \mathrm{NO}_{5} \mathrm{Si}$ : 500.2832; Found: 500.2834.

FTIR (film): 3441, 3053, 2965, 2933, 2860, 2306, 1963, 1709, 1589, 1501, 1473, 1428, $1392,1367,1266,1170,1113,913,872,823 \mathrm{~cm}^{-1}$.

$[\alpha]_{\mathrm{D}}=+11.8\left(\mathrm{c}=2.96, \mathrm{CHCl}_{3}\right)$. 


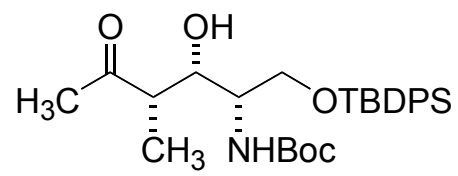

\section{${ }^{1}$ H NMR Spectrum}

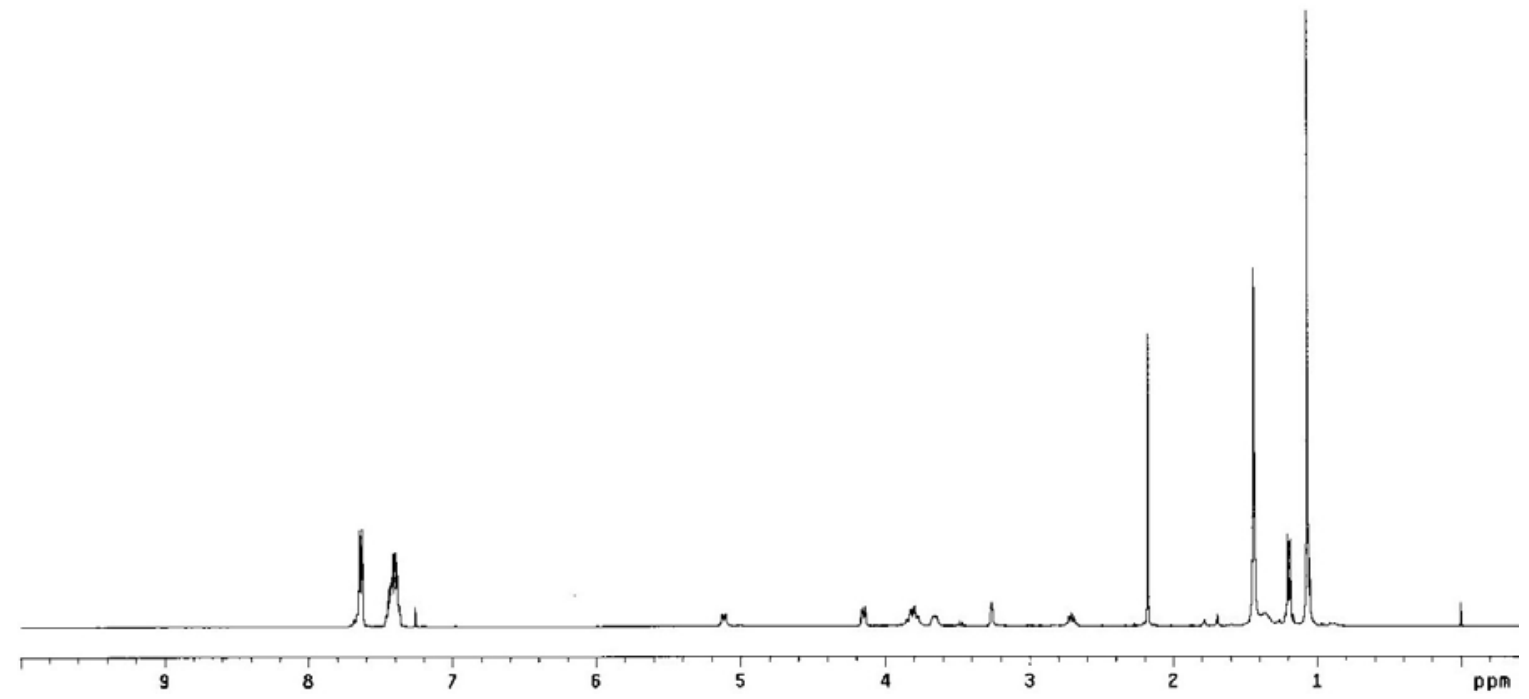

\section{${ }^{13}$ C NMR Spectrum}

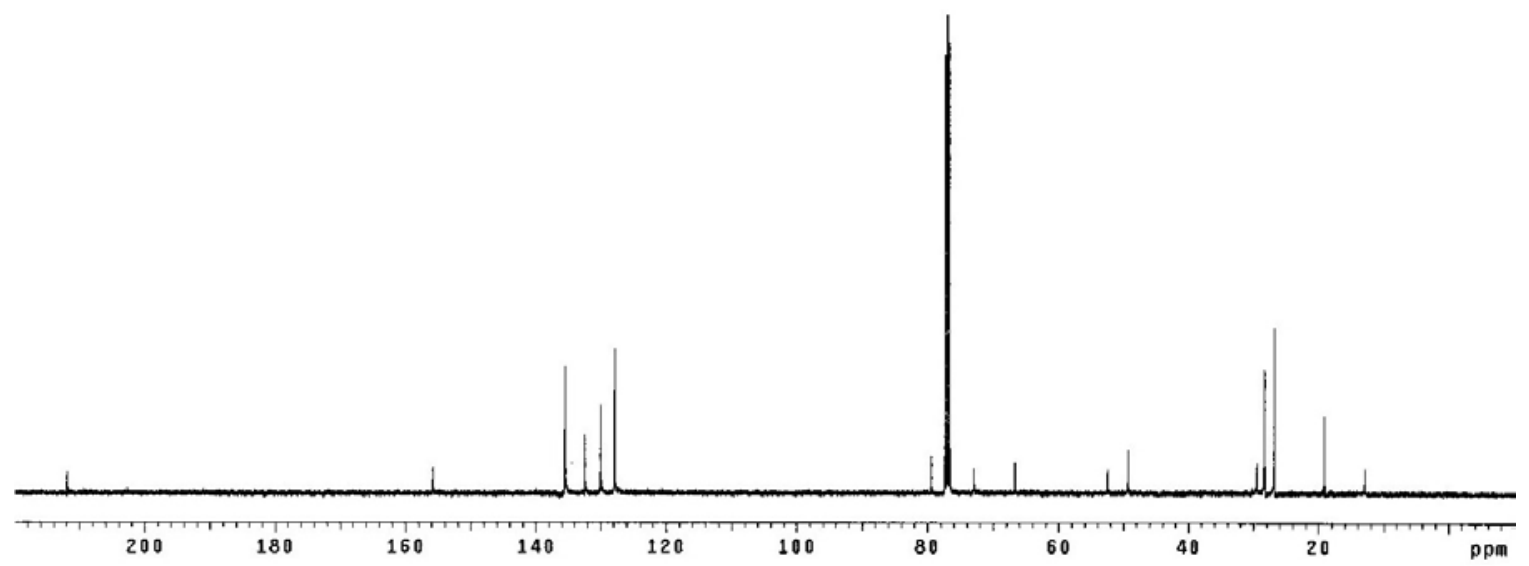




\section{(1S,2S,3S)-[1-(tert-Butyl-diphenyl-silanyloxymethyl)-2-hydroxy-3-methyl-4-oxo-}

pentyl]-carbamic acid tert-butyl ester (8b) - alternate reaction conditions involving tert-amyl alcohol as an additive.

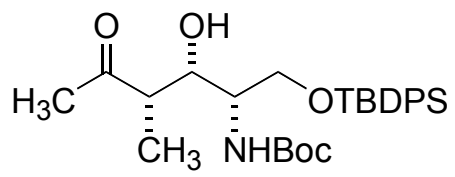

To a $13 \mathrm{~mm} \times 100 \mathrm{~mm}$ test-tube were added $\mathrm{Li}_{2} \mathrm{CO}_{3}(1.3 \mathrm{mg}, 10 \mathrm{~mol} \%)$, (2-furyl) ${ }_{3} \mathrm{P}(4.9$ mg, $12 \mathrm{~mol} \%$ ), Rh(COD) 2 OTf (4.1 mg, $5 \mathrm{~mol} \%$ ), $N$-Boc- $O$-TBDPS-L-serinal (75.5 mg, $100 \mathrm{~mol} \%)$, dichloromethane $(0.18 \mathrm{~mL}, 1.0 \mathrm{M})$ and 2-methyl-2-butanol $(0.19 \mathrm{ml}, 1000$ $\operatorname{mol} \%)$. Then the test-tube was sealed and the reaction system was purged with $\operatorname{Ar}(\mathrm{g})$ and $\mathrm{H}_{2}$ (g) for 20 seconds each. The reaction system was placed under one atmosphere of hydrogen using a balloon and methyl vinyl ketone (108 $\mu \mathrm{L}, 300 \mathrm{~mol} \%)$ was added to the reaction mixture. The reaction mixture was allowed to stir at $25{ }^{\circ} \mathrm{C}$ for 16 hours. The title compound was purified by flash chromatography $\left(\mathrm{SiO}_{2}\right.$ : EtOAc/Hexane) to afford 74.1 mg of colorless oil ( $85 \%$ yield, dr 7:1).

\section{$\underline{{ }^{1} \text { H NMR Spectrum }}$}

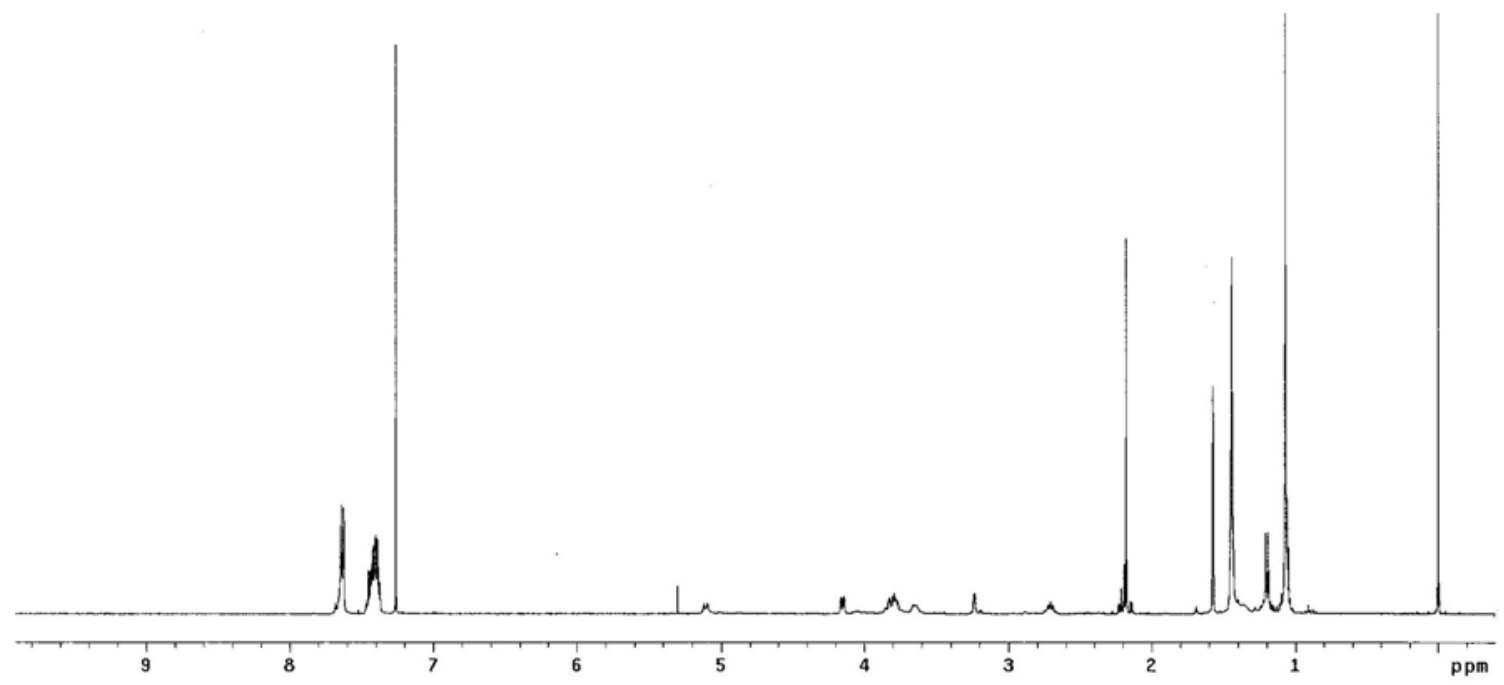




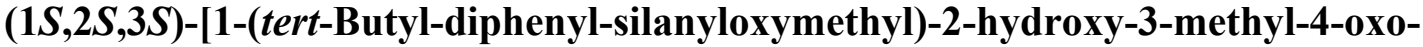

hexyl]-carbamic acid tert-butyl ester (8c).

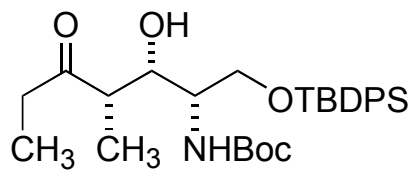

To a $13 \mathrm{~mm} \times 100 \mathrm{~mm}$ test-tube were added $\mathrm{Li}_{2} \mathrm{CO}_{3}(3.8 \mathrm{mg}, 10 \mathrm{~mol} \%$ ), (2-furyl) 3 P (14.2 $\mathrm{mg}, 12 \mathrm{~mol} \%$ ), $\mathrm{Rh}(\mathrm{COD})_{2} \mathrm{OTf}(11.9 \mathrm{mg}, 5 \mathrm{~mol} \%$ ), $N$-Boc- $O$-TBDPS- L-serinal (219 mg, $100 \mathrm{~mol} \%)$ and dichloromethane $(0.51 \mathrm{~mL}, 1.0 \mathrm{M})$. Then the test-tube was sealed and the reaction system was purged with $\operatorname{Ar}(\mathrm{g})$ and $\mathrm{H}_{2}(\mathrm{~g})$ for 20 seconds each. The reaction system was placed under one atmosphere of hydrogen using a balloon and ethyl vinyl ketone $(152 \mu \mathrm{L}, 300 \mathrm{~mol} \%)$ was added to the reaction mixture. The reaction mixture was allowed to stir at $25{ }^{\circ} \mathrm{C}$ for 16 hours. The title compound was purified by flash chromatography $\left(\mathrm{SiO}_{2}\right.$ : EtOAc/Hexane) to afford $231 \mathrm{mg}$ of yellowish solid (88 \% yield).

TLC $: \mathrm{R}_{f} 0.6$ (Hexane/EtOAc, 2/1).

1H NMR $\left(400 \mathrm{MHz}, \mathrm{CDCl}_{3}\right): \delta 7.63-7.69(\mathrm{~m}, 4 \mathrm{H}), 7.38-7.46(\mathrm{~m}, 6 \mathrm{H}), 5.17(\mathrm{~d}, J=9.2 \mathrm{~Hz}$, $1 \mathrm{H}), 4.15-4.18(\mathrm{~m}, 1 \mathrm{H}), 3.82\left(\mathrm{dd}, \mathrm{A}\right.$ of $\left.\mathrm{ABX}, J_{A B}=10.6 \mathrm{~Hz}, J_{A X}=3.8 \mathrm{~Hz}, 1 \mathrm{H}\right), 3.78(\mathrm{dd}$, $\mathrm{B}$ of $\left.\mathrm{ABX}, J_{A B}=10.6 \mathrm{~Hz}, J_{B X}=4.3 \mathrm{~Hz}, 1 \mathrm{H}\right), 3.59-3.61(\mathrm{~m}, 1 \mathrm{H}), 3.30(\mathrm{~d}, J=2.7 \mathrm{~Hz}, 1 \mathrm{H})$, 2.75 (quintet, $J=7.3 \mathrm{~Hz}, 1 \mathrm{H}), 2.41-2.60(\mathrm{~m}, 2 \mathrm{H}), 1.44(\mathrm{~s}, 9 \mathrm{H}), 1.18(\mathrm{~d}, J=6.5 \mathrm{~Hz}, 3 \mathrm{H})$, $1.07(\mathrm{~s}, 9 \mathrm{H}), 1.03(\mathrm{~d}, J=7.4 \mathrm{~Hz}, 3 \mathrm{H})$.

${ }^{13} \mathrm{C} \mathrm{NMR}\left(100 \mathrm{MHz}, \mathrm{CDCl}_{3}\right): \delta 214.6$ 155.7, 135.5, 135.5, 132.4, 129.9, 127.8, 79.3, $73.1,66.7,52.4,48.4,35.4,28.3,26.8,13.3,7.5$.

HRMS: Calcd [M] for $\mathrm{C}_{29} \mathrm{H}_{43} \mathrm{NO}_{5} \mathrm{Si}$ : 514.2989; Found: 514.2991.

FTIR (film): 3443, 3072, 3052, 2977, 2934, 2860, 1962, 1900, 1822, 1705, 1590, 1502, $1462,1428,1392,1367,1263,1170,1112,1043,1025,975,857,824 \mathrm{~cm}^{-1}$.

MP: $102-103^{\circ} \mathrm{C}$.

$[\alpha]_{\mathrm{D}}=+9.8\left(\mathrm{c}=2.05, \mathrm{CHCl}_{3}\right)$. 


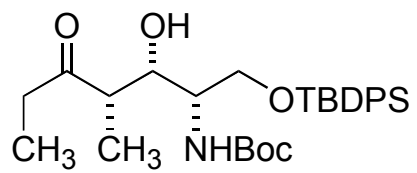

\section{${ }^{1}$ H NMR Spectrum}

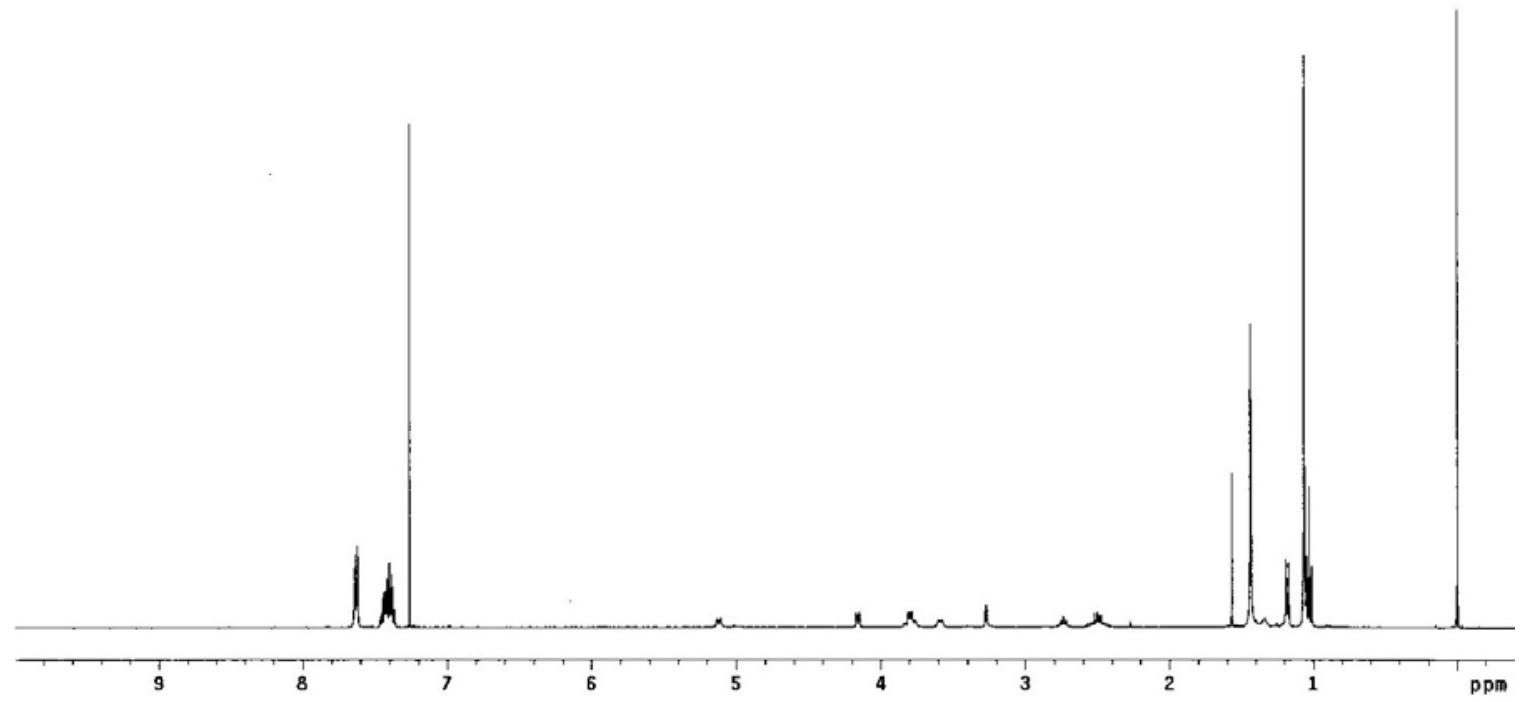

\section{${ }^{13}$ C NMR Spectrum}

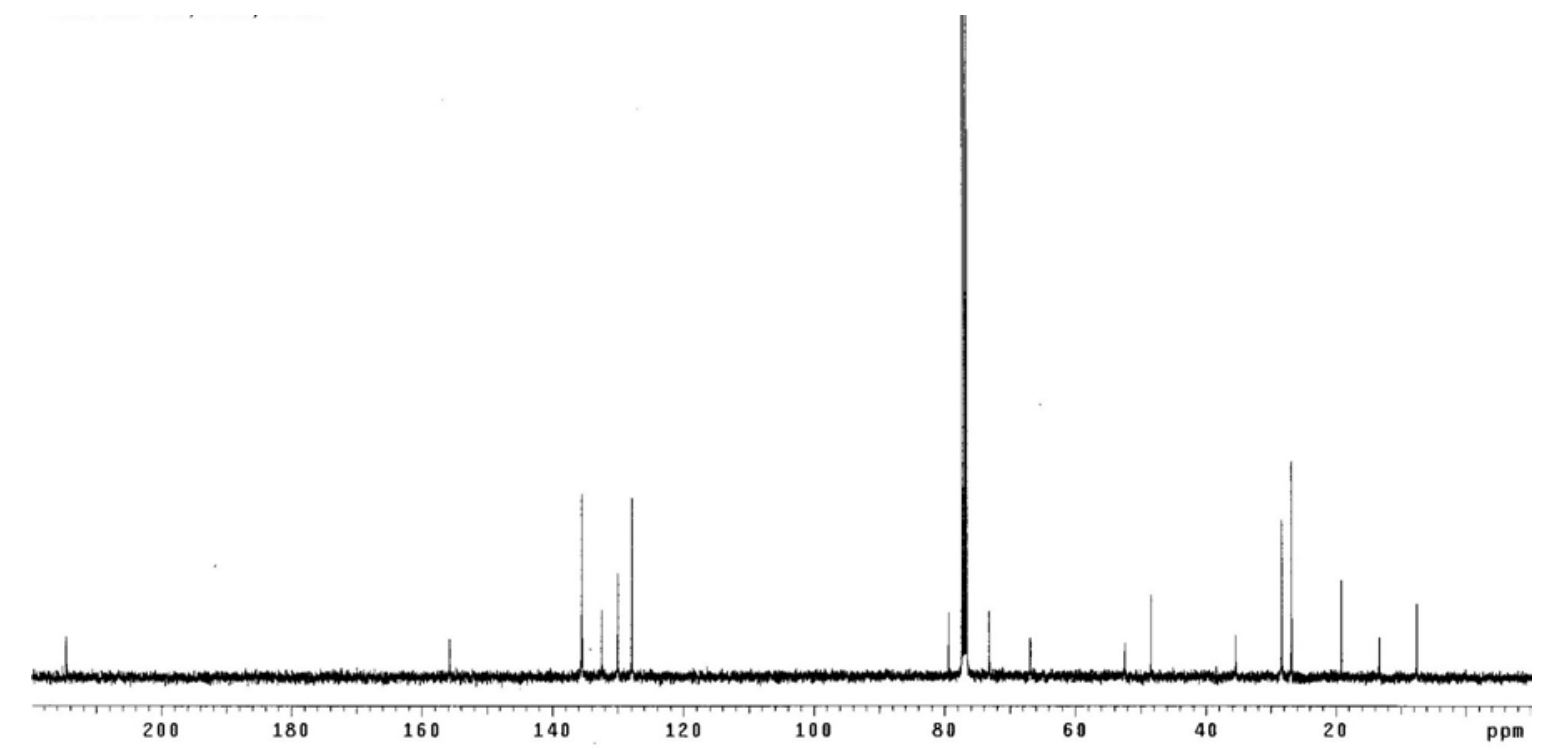




\section{Determination of Relative Stereochemistry}

The aldol product $\mathbf{5 b}$ and $\mathbf{N}-\mathbf{M e - 5 b}$ were converted to the corresponding 3,5dinitrobenzoate to give single crystals for X-ray determination.

\section{3,5-Dinitro-benzoic acid (1S,2S)-2-tert-butoxycarbonylamino-4-methyl-1-[(1S)-1-} methyl-2-oxo-propyl]-pentyl ester (3,5-dinitrobenzoate of $5 \mathbf{b})$.<smiles>CC(=O)OCC(C)N[C@@H](CC(=O)O)[C@H](OC(=O)c1cc([N+](=O)[O-])cc([N+](=O)[O-])c1)[C@@H](C)C(C)=O</smiles>

A solution of alcohol $\mathbf{5 b}(79 \mathrm{mg}, 100 \mathrm{~mol} \%)$ in DCM $(1.4 \mathrm{~mL}, 0.2 \mathrm{M})$ was placed in $0{ }^{\circ} \mathrm{C}$ bath and placed under Ar atmosphere. To the reaction mixture was added triethylamine (115 $\mu \mathrm{L}, 300 \mathrm{~mol} \%$ ) and 3,5-dinitrobenzoyl chloride (70 $\mathrm{mg}, 110 \mathrm{~mol} \%$ ). The reaction mixture was allowed to stir for 5 hours at ambient temperature. The reaction mixture was diluted with DCM and organic layer was washed with water, dried $\left(\mathrm{MgSO}_{4}\right)$, filtered and evaporated. The title compound was purified by flash chromatography $\left(\mathrm{SiO}_{2}\right.$ : EtOAc/Hexane) to afford $27 \mathrm{mg}$ as a white solid and $61 \mathrm{mg}$ of alcohol $\mathbf{5 b}$ was recovered (21\% yield, $92 \%$ conversion yield).

TLC : $\mathrm{R}_{f} 0.65$ (Hexane/EtOAc, 3/1).

${ }^{1} \mathbf{H}$ NMR $\left(400 \mathrm{MHz}, \mathrm{CDCl}_{3}\right): \delta 9.26(\mathrm{t}, J=2.2 \mathrm{~Hz}, 1 \mathrm{H}), 9.16(\mathrm{~d}, J=2.2 \mathrm{~Hz}, 2 \mathrm{H}), 5.63$ $(\mathrm{dd}, J=3.2,8.5 \mathrm{~Hz}, 1 \mathrm{H}), 4.44(\mathrm{~d}, J=9.8 \mathrm{~Hz}, 1 \mathrm{H}), 4.01-4.08(\mathrm{~m}, 1 \mathrm{H}), 3.10$ (quintet, $J=$ $7.5 \mathrm{~Hz}, 1 \mathrm{H}), 2.27(\mathrm{~s}, 3 \mathrm{H}), 1.64-1.73(\mathrm{~m}, 1 \mathrm{H}), 1.42(\mathrm{~s}, 9 \mathrm{H}), 1.23-1.30(\mathrm{~m}, 2 \mathrm{H}), 1.17(\mathrm{~d}, J=$ $7.2 \mathrm{~Hz}, 3 \mathrm{H}), 0.92(\mathrm{~d}, J=6.7 \mathrm{~Hz}, 3 \mathrm{H}), 0.91(\mathrm{~d}, J=6.5 \mathrm{~Hz}, 3 \mathrm{H})$.

${ }^{13} \mathbf{C ~ N M R}\left(100 \mathrm{MHz}, \mathrm{CDCl}_{3}\right): \delta 209.0,162.1,155.7,148.7,129.5,122.6,79.9,79.1,49.8$, $47.3,41.5,29.0,28.2,24.8,23.0,21.8,13.1$.

HRMS: Calcd [M] for $\mathrm{C}_{22} \mathrm{H}_{31} \mathrm{~N}_{3} \mathrm{O}_{9}$ : 481.2060; Found: 481.2057.

FTIR (film): 3412, 3104, 2960, 2256, 1733, 1702, 1628, 1548, 1508, 1460, 1392, 1366, $1345,1270,1163,1120,1076,1016,912 \mathrm{~cm}^{-1}$.

MP: $104-106^{\circ} \mathrm{C}$. 
<smiles>CC(=O)OCC[C@H](N)[C@H](OC(=O)c1cc([N+](=O)[O-])cc([N+](=O)[O-])c1)[C@@H](C)C(C)=O</smiles>

\section{${ }^{1}$ H NMR Spectrum}

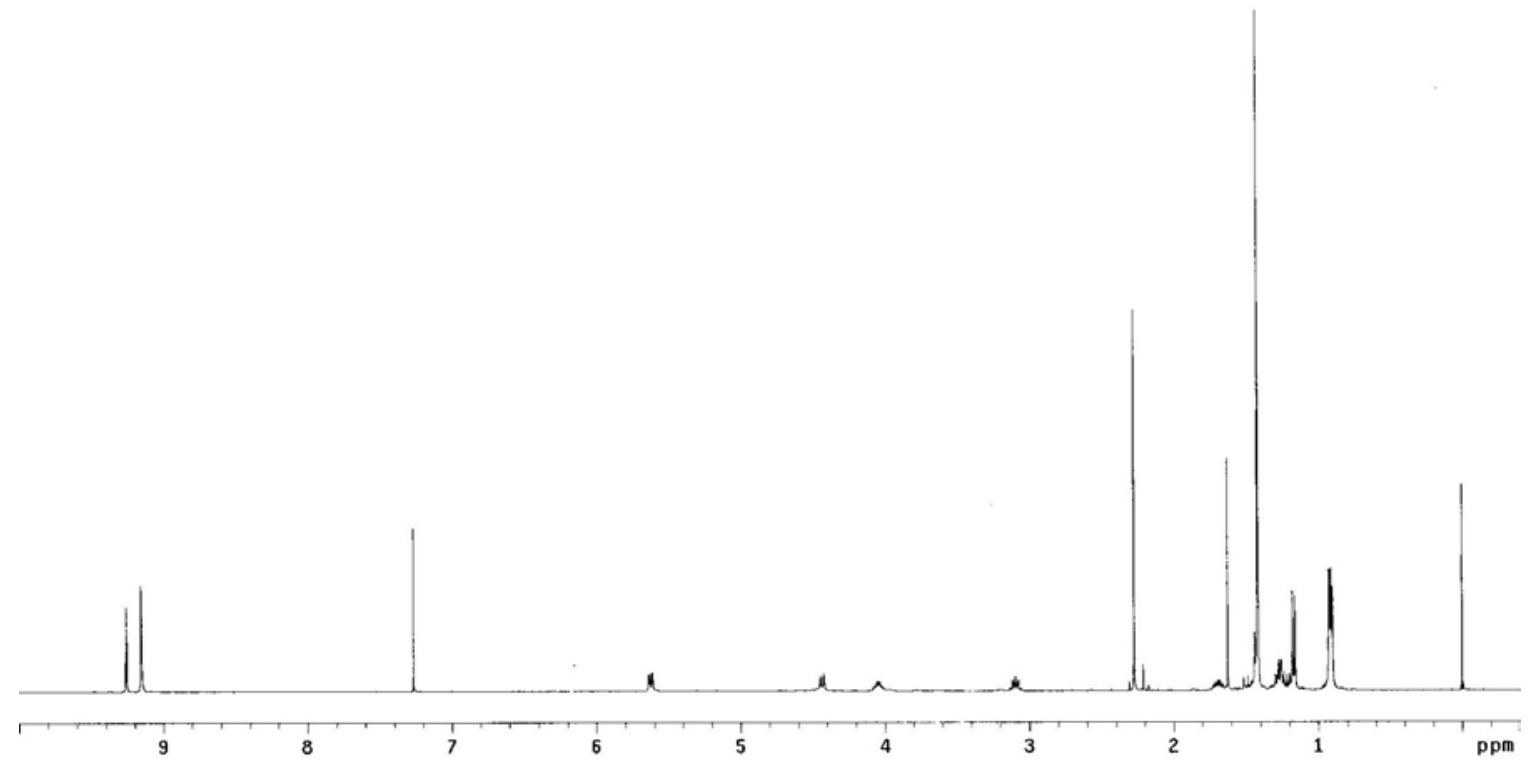

\section{${ }^{13}$ C NMR Spectrum}

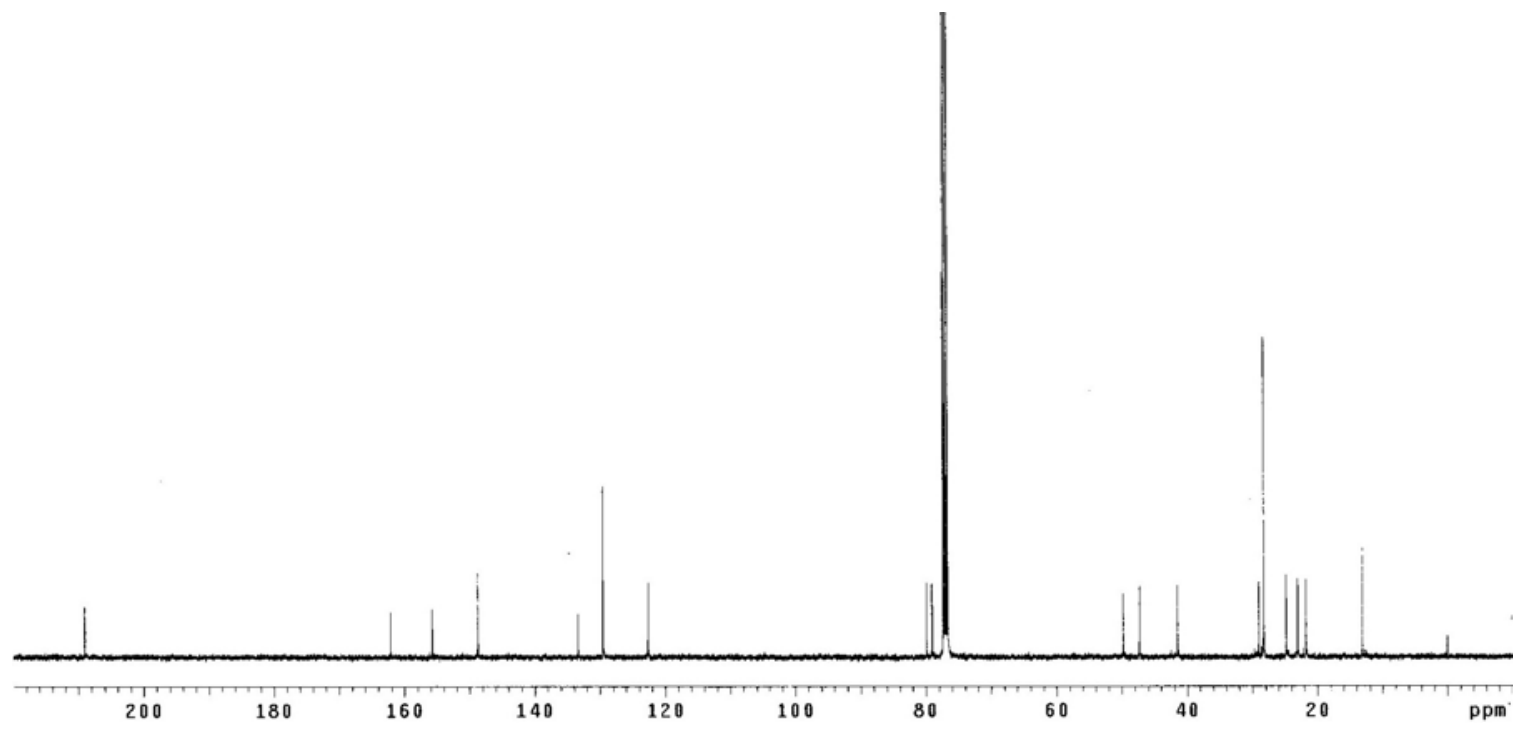




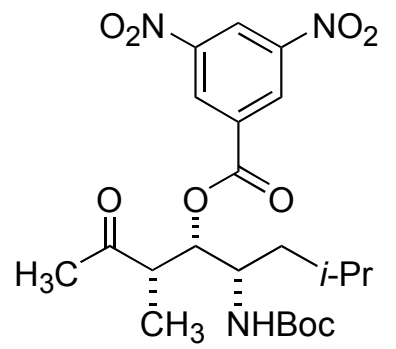

Unit cell packing diagram: The view is approximately down the b-axis. Dashed lines are indicative of $\mathrm{H}$-bonding interactions.

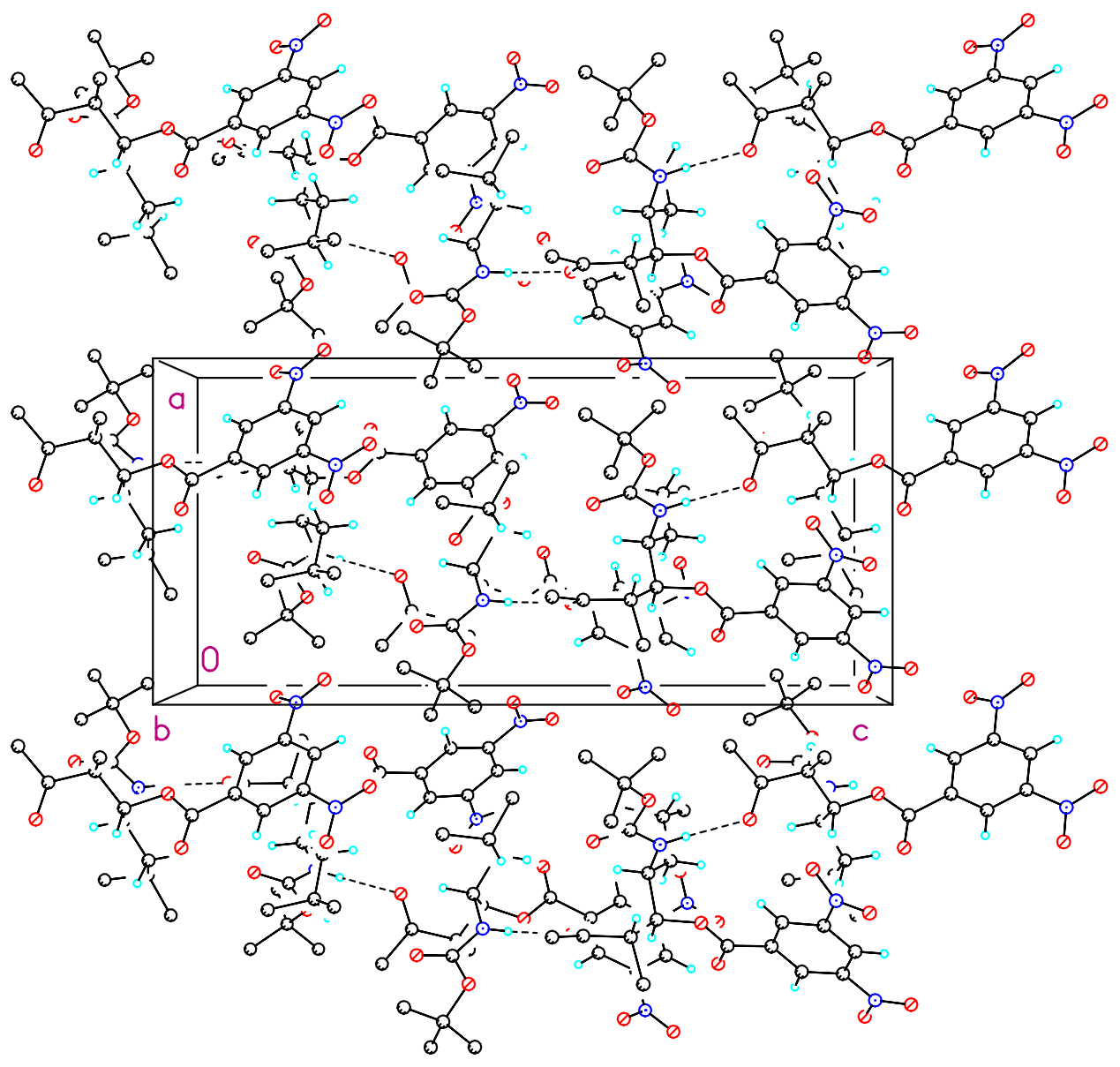


$(1 S, 2 R, 3 R)$-(2-Hydroxy-1-isobutyl-3-methyl-4-oxo-pentyl)-carbamic acid tert-butyl ester (iso-5b).<smiles>[R6]NC(CC(C)C)C(O)C(C)C(C)=O</smiles>

Unit cell packing diagram: The view is approximately down the a axis. Molecules 2 are shown in wireframe form, while molecules 1 are in ball-and-stick format. The molecules H-bond in columns parallel to the a axis.

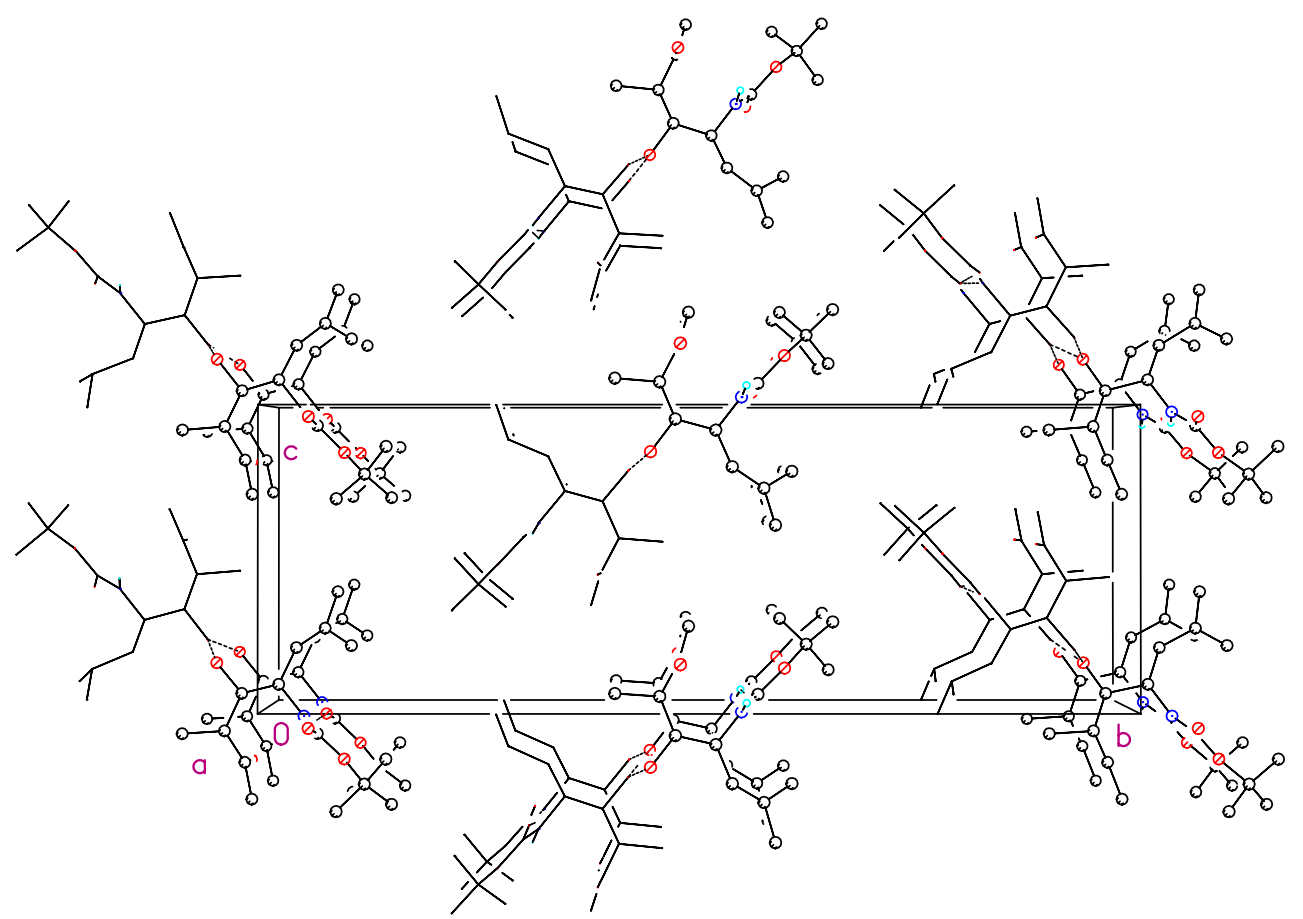




\section{3,5-Dinitro-benzoic acid (1R,2S)-2-(tert-butoxycarbonyl-methyl-amino)-4-methyl-1-}

[(1R)-1-methyl-2-oxo-propyl]-pentyl ester (3,5-dinitrobenzoate of $\mathrm{N}$-Me-5b).<smiles>CC(=O)C[C@H](C)C(OC(=O)c1cc([N+](=O)[O-])cc([N+](=O)[O-])c1)[C@@H](C)C(=O)O</smiles>

A solution of alcohol $\mathbf{N}$-Me-5b (30 mg, $100 \mathrm{~mol} \%)$ in DCM (0.5 mL, $0.2 \mathrm{M})$ was placed in $0{ }^{\circ} \mathrm{C}$ bath and placed under Ar atmosphere. To the reaction mixture was added triethylamine (42 $\mu \mathrm{L}, 300 \mathrm{~mol} \%)$ and 3,5-dinitrobenzoyl chloride (25 mg, $110 \mathrm{~mol} \%$ ). The reaction mixture was allowed to stir for 20 hours at ambient temperature. The reaction mixture was diluted with DCM and organic layer was washed with water, dried $\left(\mathrm{MgSO}_{4}\right)$, filtered and evaporated. The title compound was purified by flash chromatography $\left(\mathrm{SiO}_{2}\right.$ : EtOAc/Hexane) to afford $20 \mathrm{mg}$ as a white solid and $17 \mathrm{mg}$ of alcohol $N$-Me-5b was recovered (40\% yield, $70 \%$ conversion yield).

TLC: $\mathrm{R}_{f} 0.7$ (Hexane/EtOAc, 3/1).

HRMS: Calcd [M] for $\mathrm{C}_{23} \mathrm{H}_{32} \mathrm{~N}_{3} \mathrm{O}_{9}$ : 495.2217; Found: 495.2216.

FTIR (film): 3444, 2961, 2254, 1737, 1685, 1629, 1549, 1461, 1392, 1368, 1345, 1274, $1162,1077,908 \mathrm{~cm}^{-1}$.

MP: $99-101{ }^{\circ} \mathrm{C}$. 
<smiles>CC(=O)C[C@H](C)C(OC(=O)c1cc([N+](=O)[O-])cc([N+](=O)[O-])c1)[C@@H](C)C(=O)OCc1ccccc1</smiles>

Unit cell packing diagram: The view is approximately down the $\mathbf{b}$ axis.

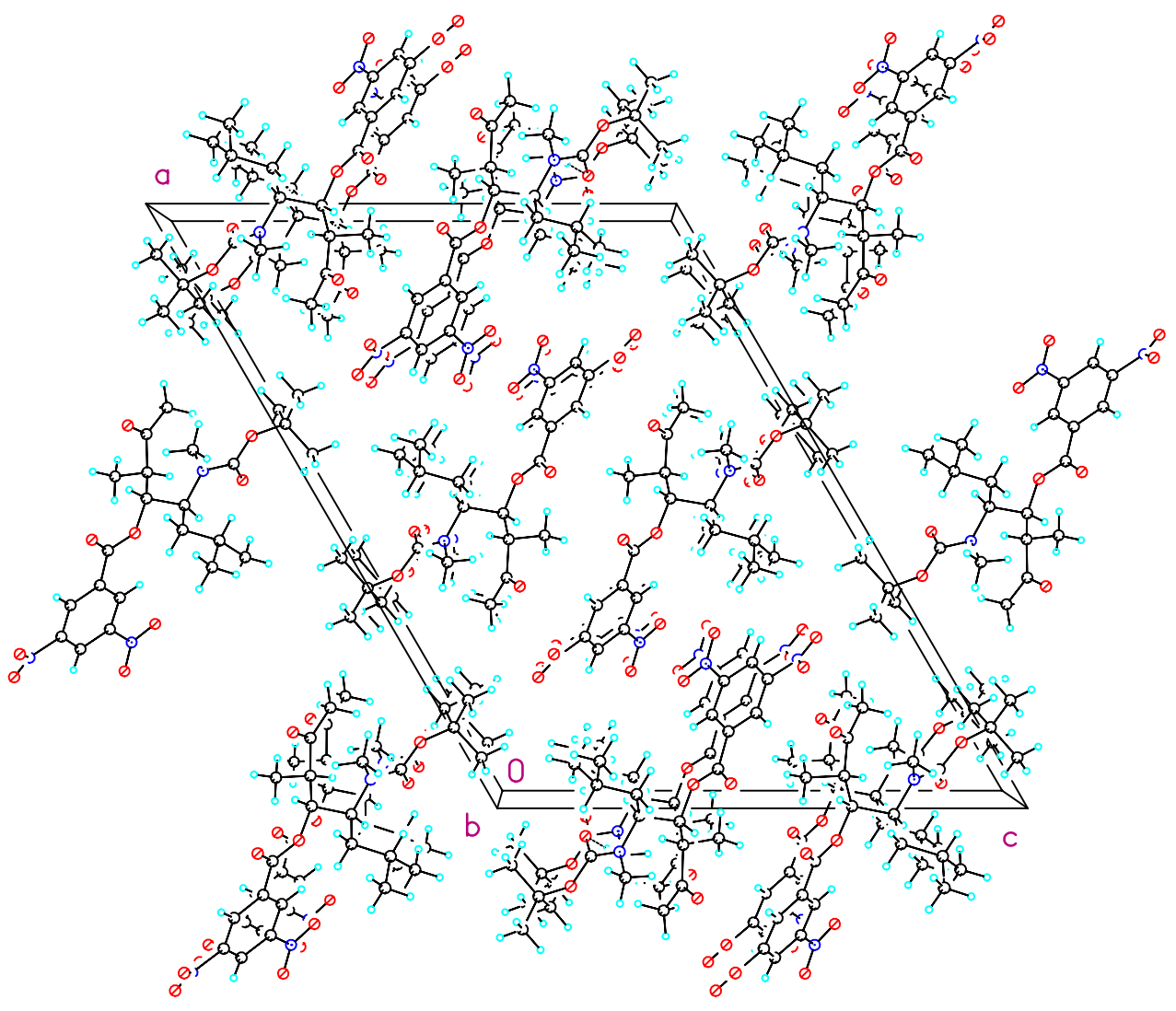


(1S,2S,3S)-2-Hydroxy-1-isopropyl-3-methyl-4-oxo-pentyl)-carbamic acid tert-butyl ester (7b).<smiles>CC(=O)[C@H](O)[C@H](N)C(C)C(C)C(=O)O</smiles>

Unit cell packing diagram: The view is approximately down the a axis. Molecules 1 are shown in ball-and-stick form while molecules 2 are in wireframe display format.

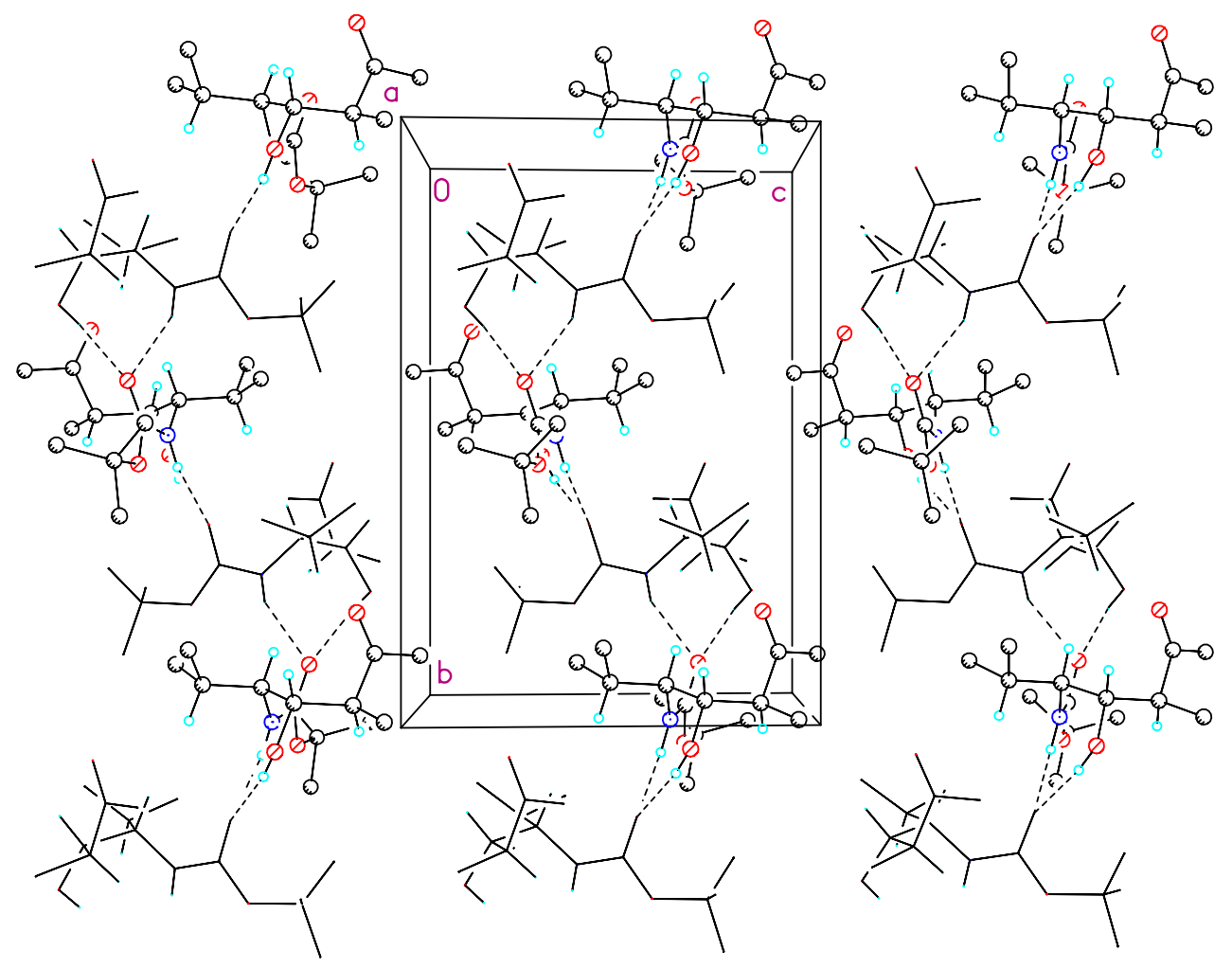

